Presented at the $32 d$ Annual Convention of the American Institute of Electrical Engineers,

Deer Park, Md., June 29, 1915.

Copyright 1915. By A. I. E. E.

\title{
ELECTRICITY IN GRAIN ELEVATORS
}

\author{
BY H. E. STAFFORD
}

\section{Abstract OF PAPER}

The object of this paper is to show the storage capacity of grain at the terminals of Port Arthur and Fort William, the rated horse power capacity of prime movers, the amount of power used to turn out a given quantity of grain, and the power used by different machines in the process. In addition it gives the details of different plants as regards construction and operation and the method of receiving and shipping grain. It gives a comparison between steam and electrically-driven plants as regards convenience, maintenance, operation and cost. As regards the station end, it shows the lay-out of different stations, the cost of installation, the operation and in some instances, the cost of power. It will be shown in the paper that the cost of handling grain varies, and the reason is fully described. On account of the grain handling season being of short duration, it is the intention of certain companies to install turbo-generators to overcome the necessity of paying on a peak demand basis. By installing two or more units the operating expenses would be cut to a minimum. With the use of steam power this is impossible.

FLECTRIC power first came into the limelight in this industry in Fort William, in 1902, making this city one of the pioneers in this respect. Electricity was first introduced by the Canadian Pacific Railway, which built a power house operated by steam, for the purpose of electrifying its numerous elevators. This company was the only one using electric power until the advent of the Kaministiqua Power Co., in 1905. The latter company established a power house at the foot of Kakebeka Falls, 18 miles from Fort William, in June 1905, and the first two units of 7000 h.p. capacity were put into operation in December, 1906. A third unit of 7000 h.p. was added in October, 1911, while a fourth unit of 13,000 h.p. was added in August, 1914, making a total of 27,000 h.p. Fig. 1 shows the location of the power house and flumes.

At this point the power is generated at 4000 volts, and stepped up to $25 \mathrm{kv}$. It is transmitted at this voltage to substations at Port Arthur and Fort William, where it is stepped 
down to 2200 volts. The loss in transmission is approximately 3000 volts.

The substation at Fort William has, at present, three banks of three transformers with a capacity of $5500 \mathrm{kv}$-a. for each bank. The station at Port Arthur has six transformers of 750 $\mathrm{kv}-\mathrm{a}$. each. The connections from power house to station are star-star, star-delta, with grounded neutral. The Corporation of Port Arthur has in addition, a hydroelectric plant at Current River with a total capacity of $2500 \mathrm{kv}-\mathrm{a}$., at 2200 volts, which is used at the heaviest load period to keep down the peak.

Under the names of the different plants will be given a brief description of the various conditions under which they work, obtain power, etc. The first two described are the latest built, and will be given in detail.

\section{Western Terminal Elevator}

This elevator is a recent type, and is the second in Fort William to purchase power at $22 \mathrm{kv}$. The station was completed in August, 1914. The old plant which was built a few years ago is of concrete, with steel and tile cupola, while the tanks are tile. The new house, built in 1914, is of reinforced concrete throughout. The building is built on a foundation of piles driven sixty feet below cut-off. The piles are driven in blue clay, and are capable of standing a stress of between 16 and 20 tons per pile. The grain capacity of the elevator is $2,000,000$ bushels. The power contracted for is 700 h.p. The plant is equipped with 56 motors of a total capacity of $1140 \frac{1}{2}$ h.p. The motors are used for various purposes, some of which are given below.

There are two car-haul motors (one for each track) of 40 h.p. capacity each, capable of hauling 25 cars each. There are six receiving pits and three receiving legs with 22 -inch buckets. Each leg is operated by a 75-h.p. motor. The distributing belt conveyers are operated by a 20 -h.p. motor each, and the shipping belt conveyers are operated by a 15-h.p. motor each. The loading legs require from 60-h.p. to 75-h.p. motors each.

There are also seven cleaners and three cleaning legs. The cleaner legs take from 15 h.p. to 25 h.p. each, while the cleaners are operated by a 10-h.p. motor each. This plant is equipped with four flax machines, of 10-h.p. capacity each, and two special flax machines of $7 \frac{1}{2}$ h.p. each. 
Two fans for collecting dust are operated by a 10-h.p. and 15-h.p. motor respectively, and the building is piped with compressed air supplied by a $4 \frac{1}{2}$ - by 6 -in. compresser for cleaning motors.

The station equipment consists of three $250-\mathrm{kv}$-a. singlephase transformers. The connections are star-delta. The power factor is kept at 90 per cent by two $125-\mathrm{kv}$-a. condensers. In addition there is a $30-\mathrm{kw}$. single-phase transformer for lighting purposes. The load factor is about 25 per cent.

\section{Fort William Elevator Co.}

This plant was built in 1913 and is of reinforced concrete with brick paneling. The plant, which has a grain capacity of 1,500,000 bu., is operated by both steam and electric power. The boiler capacity (four hoilers) is 500 h.p. The engine capacity is 800 h.p. These operate at a steam pressure of $120 \mathrm{lb}$.

The electric plant consists of a 300-h.p. marine engine directconnected to a 225-kw., 600-volt, 60-cycle, three-phase alternator supplying current to three 100-h.p. motors operating three shipping legs, four 15-h.p. motors operating four shipping conveyer belts, and one 20-h.p. motor operating a reversible conveyer belt.

The plant uses 2000 tons of coal per annum at a cost of $\$ 4.00$ per ton. Below is given the cost of operating the plant for one year.

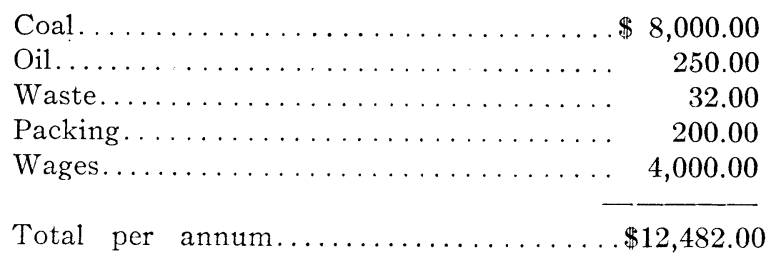

This makes an average of $\$ 34.194$ per day. Average load for 365 days $=300$ h.p. Average cost per h.p. per annum = \$41.606. As this plant also supplies steam for the drier, the actual cost is somewhat below this amount, the actual cost not being known.

The storage capacity of the plant is 48 tanks, each containing 27,000 bu., and 35 intermediate tanks, each containing $7000 \mathrm{bu}$. There are six receiving pits capable of handling 12 cars or $13,200 \mathrm{bu}$. per hour. Also nine wheat cleaners and two flax cleaners of $1000 \mathrm{bu}$. capacity per hour. 
The shipping capacity is about 45,000 bu. per hour, and each conveyer belt of 15 h.p. capacity handles 20,000 bu. per hour. Two extra features of this plant are a separater, for separating various grains, and a drying plant. The capacity of the drier is $1000 \mathrm{bu}$. per hour.

\section{Consolidated Elevator}

The total grain capacity of this plant is $1,750,000 \mathrm{bu}$. Power is delivered at 2200 volts on a contract basis of 700 h.p. The average load is 600 h.p. The total number of motors is 37 , ranging from 2 h.p. to 75 h.p., delivering 1007 h.p.

The transformer station consists of 2200 to 600 -volt transformers, a synchronous condenser, necessary switch gear, and motors. All other characteristics correspond to the plants previously described.

\section{Canadian Pacific Railway Co.}

As before stated, the C. P. R. was the pioneer in the use of electric power for elevator purposes. This plant, which is the only one operated by this company in this city, has a total grain capacity of $8,000,000 \mathrm{bu}$. and is the second largest plant in the world. The shipping capacity is 80,000 bu. per hour.

The company discontinued the use of its own power plant and purchased power from the Kaministiqua Power Co. in 1907. Power is purchased at 2200 volts and stepped to 600 volts at its own transformer station. The transformer capacity is three single-phase, $588-\mathrm{kv}$-a., or a total of $1764 \mathrm{kv}$-a. The power factor is maintained at 90 per cent by a $750 \mathrm{kv}-\mathrm{a}$. condenser. The total motor capacity is 2100 h.p., while the average load is 1400 h.p.

\section{Canadian Northern Railmay Elevator}

This plant is a double one; that is, there are two work houses with the storage tanks between. It has a storage capacity of $9,500,000 \mathrm{bu}$. and is the largest plant in the world. This plant was first started in 1900 , and has been added to at various times, the last addition being made in 1913. Up to that time it was a steam plant throughout, but when the annex was built in 1913 , a $200-\mathrm{kv}$-a. three-phase generator was installed to supply power for it alone.

The total engine capacity of the plant is 2000 h.p. supplied by a 1250-h.p. and a 750-h.p. unit. The coal consumption of 
PLATE LXXI.

A. I. E. E.

VOL. XXXIV, 1915

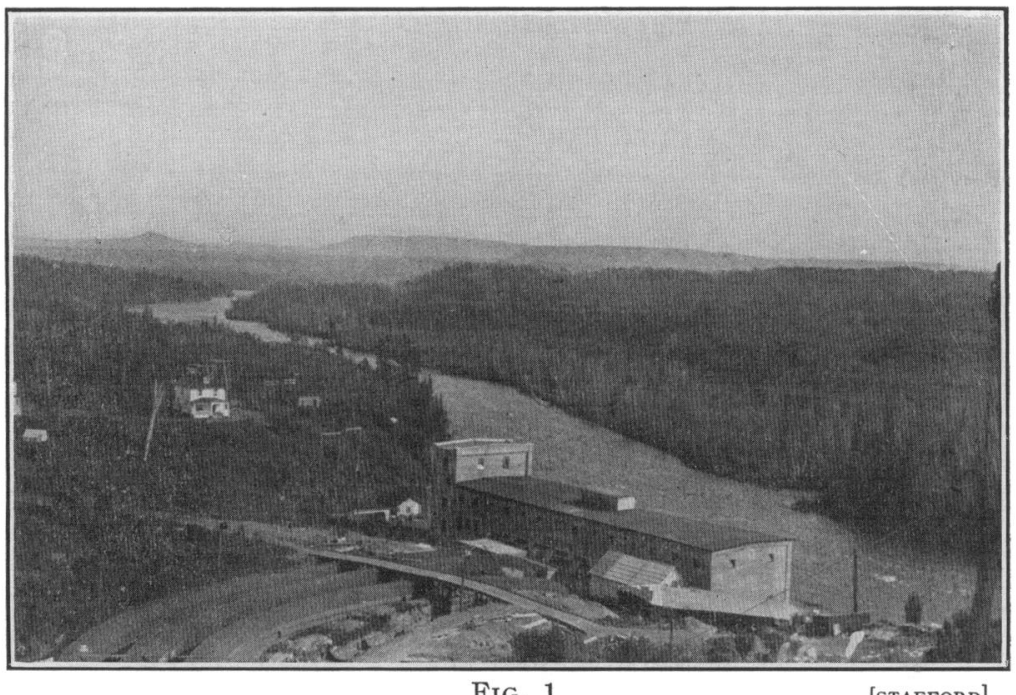

FIG. 1

[STAFFORD]

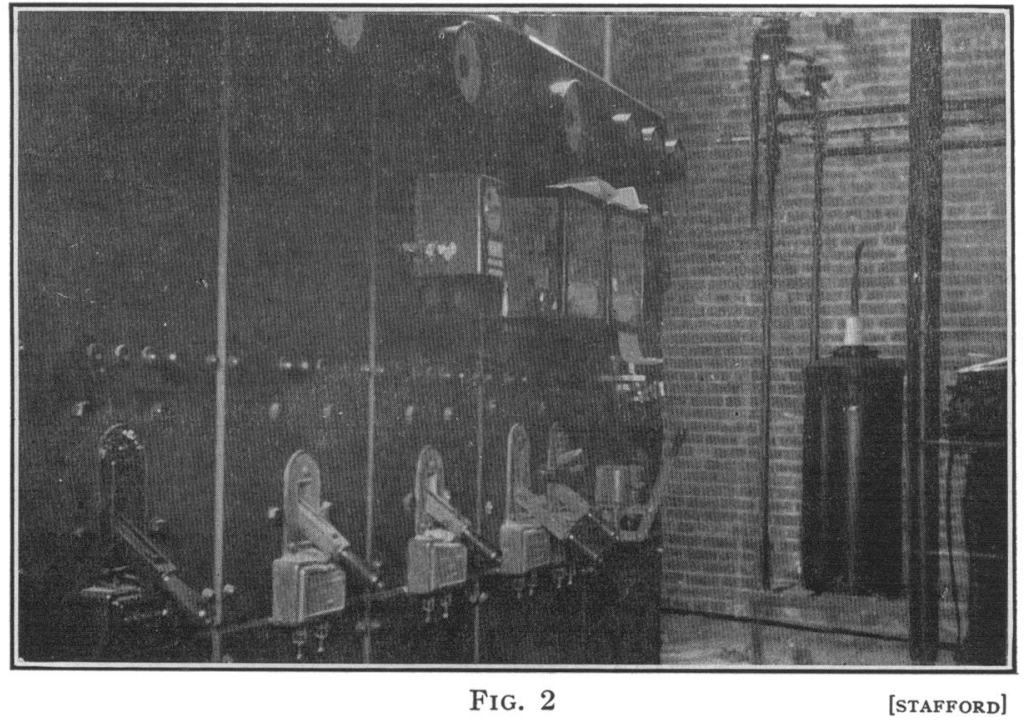


this plant is 7000 tons per annum, 950 tons of which are used in the driers. The average horse power (steam) is about 1700 . The cost of producing power is 0.9 cent per $\mathrm{kw}$-hr. figured on a basis of $3 \frac{1}{2} \mathrm{lb}$. of coal per h.p-hour. Statistics of this plant also show that the cost for one year was $\$ 22.56$ per h.p. for steam power which is an exceedingly low rate.

The average amount of grain handled in one year is $40,000,000$ bu.

In Jan. 1914, the elevator was remodeled, necessitating the installation of additional power. As the company was considering using electric power throughout in the near future, it was deemed advisable to erect a substation to accommodate the extra power needed, which could be enlarged as more power was required.

The transformer station is a separate building of brick and tile construction, and was built in 1913. The equipment, which was installed and partly designed by the writer, was put in operation in April 1914. Power is purchased from the City of Port Arthur, at $22 \mathrm{kv}$., and stepped to 600 volts by three 150-kv-a. transformers connected to a six-panel board. The oil switches and busbars are mounted directly on the board, which consists of one main panel, one condenser panel, and four feeders. On the main panel is an ammeter giving the readings from the high-tension side of the transformers, a graphic wattmeter giving the total kilowatts of load, a graphic power factor meter and a maximum demand and integrating wattmeter combined. The voltmeter giving the low-tension readings is mounted on a swing bracket at the end of the board. The four feeders are duplicates and have only an ammeter each, with the necessary switchgear. A detail drawing of connections is shown in Fig. 3. This diagram corresponds to nearly all the low-tension connections in all the elevators. Fig. 2 shows a view of this board and part of the lightning arrester equipment.

A detailed drawing of the synchronous condenser panel is shown in Fig. 4. This consists of three a-c. ammeters, one a-c. voltmeter, one d-c. ammeter, one d-c. voltmeter, and oil switch, two rheostats, synchronizing lamps, switches, plugs and starting controller. The condenser itself is the $200-\mathrm{kv}-\mathrm{a}$. generator mentioned before, and was installed in the station for power factor correction. The condenser is started somewhat differently from the others used in elevator practise (all others are 
self-starting) as this machine is started and brought up to speed (900 rev. per min.) by its exciter, which is supplied at 110 volts d-c. by a large generator supplying lights to the elevator. When the machine has reached synchronous speed it is thrown on the line in the usual way and the double-pole, doublethrow switch shown in Fig. 4 is thrown to the running position, when the exciter takes care of the condenser, through the generator field rheostat, by which the power factor can be regulated at will. It takes one minute to get the condenser on the line.

The emergency switch mentioned in Fig. 4 is used in case

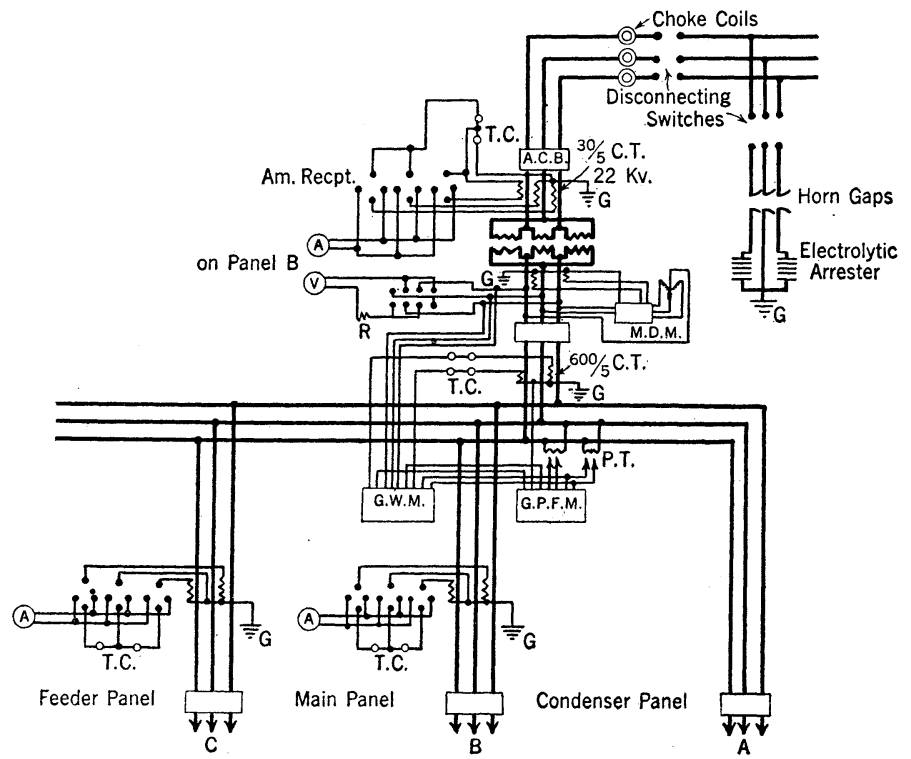

Fig. 3

C.T., current transformer; P.T., potential transformer; T.C., trip coils; A.C.B., automatic circuit breaker; M.D.M., maximum demand meter; G. W.M., graphic wattmeter; G.P.F.M., graphic power factor meter.

the exciter needs repairs. In this case the fields can still be excited from the light generator while such repairs are being made, the condenser of course having to be kept running, as there would be no way of starting it. The short-circuiting switch is for cutting out the controller when the motor is running as an exciter.

The total capacity of the switchgear is about 2000 h.p., while the capacity of the transformers is only $450 \mathrm{kv}$-a. These of course can be added to at any time. The transformers are delta-delta connected. The station is protected by three elec- 
trolytic lightning arresters. The total motor capacity at present is 765 h.p., while the average load is 385 h.p.

\section{Grand Trunk Pacific Elevator}

This elevator has a grain capacity of $5,750,000 \mathrm{bu}$. The motor capacity is 1800 h.p. It was the first in this district to purchase power at $22 \mathrm{kv}$., having contracted for it in 1909 . The substation is large and roomy with a maximum of safety. The building is three stories high. The top floor contains the

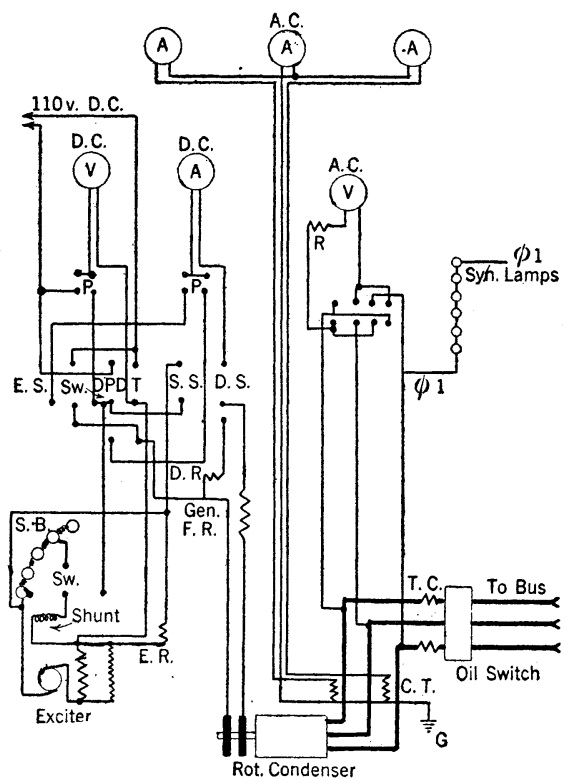

Fig. 4-Synchronous Condenser Panel

$P$. , voltmeter-ammeter plug; S.B., starting box; Gen. F.R., generator field rheostat; D.R., discharge resistance; S.S., short circuiting switch; E.S., emergency switch; D.P D.T. Sw., double pole, double throw switch; D.S., discharge switch; E.R., exciter rheostat; $C . T$., current transf ormer; T.C., trip coils.

choke coils, lightning arresters and high-tension switchgear. The arresters are the electrolytic type. The second floor contains the light and power transformers. There are three singlephase $22-\mathrm{kv}$. to 600 -volt transformers with a total capacity of $2025 \mathrm{kv}-\mathrm{a}$., and three lighting transformers of $60 \mathrm{kv}$-a. each. The ground floor is taken up with the condenser and switchboard. The condenser is self-starting and has a capacity of $750 \mathrm{kv}-\mathrm{a}$. It draws about 800 amperes at starting, and takes about $1 \frac{1}{2}$ minutes to get it on the line. The switchgear and 
buses are mounted directly on the board. An extra feature of this station is a fire pump of 500 gallons per min. capacity, driven by a 50-h.p. motor. Fig. 5 shows the elevation of a substation of this type.

\section{The Horn Elevator}

This plant, better known as "King's elevator" was built in 1883 and is the oldest elevator in this part of the country. This elevator, is an exclusive cleaning and drying plant and is called a "hospital". The grain capacity is 800,000 bu.

The plant is operated by steam, the boiler capacity being 1200 h. p. while the engine capacity is 600 h.p. The excess boiler capacity is used in the drying process. The plant is equipped with seven driers with a total capacity of 20,000 bu. per day, with grain at 8 per cent excess moisture. A full description of the drying process comes under the head of "drying," a subject discussed in the latter part of this paper.

\section{Ogilvie Milling Co.}

This company owns and operates an elevator in connection with its flour mill. The grain capacity of the elevator is 1,250 ,$000 \mathrm{bu}$., while the capacity of the mill is $3000 \mathrm{bbl}$. per day.

The rated capacity of motors is 2000 h.p. and the power

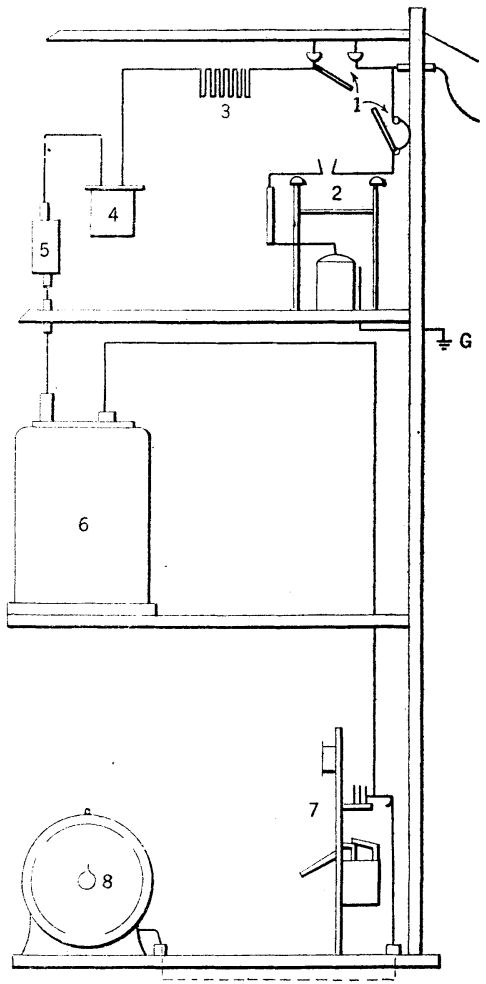

FIG. 5

1-discharge switches; 2-electrolvtic lightning arresters; 3 -choke coils; 4 -hightension oil switch; 5 -current transformer; 6-transformer; 7-switchboard; 8-con: denser.

is purchased on a 1300-h.p. demand basis. Power is delivered to the plant at 2,200 volts and stepped to 600 volts. The milling machinery is connected to a lineshaft driven by an 800-h. p. motor, while the mill cleaning equipment is lineshaft connected to a 250 -h.p. motor.

The plants described above cover the field very well, and for 
the sake of convenience, the balance of the plants at these terminals, as well as the preceding ones, are given in Table I. This table covers all the data available. It is impossible to obtain all the facts and figures, as most of the companies are very reticent in this respect.

\section{SUmmaRY}

The power applied to grain elevators, steam and electric, may be summarized as follows:

total h.p.

Electric power (max. demand)

$14,412 \frac{1}{2}$

average h.p.

8680

495

Electric power (flat rate)

475

Steam power

4,710

3105

Combined steam and electric

800 steam

365 electric

(1165 total)

300

The total capacity of all terminal elevators as shown in Table $I$ is $42,090,000 \mathrm{bu}$. The total capacity of prime movers is $19,982 \frac{1}{2}$ h.p. and the average power is 12,360 h.p. During the season of 1914, the total grain shipments from these terminals was $126,398,622$ bushels.

In connection with the types and classes of plants, a little explanation is necessary. There are two types of plants, public and private. These may belong to either of the two classes, as shown in Table I. A public plant is one in which the grain is handled on a percentage basis for any grower or grain company, while the private plant buys the grain outright and disposes of it to suit its needs.

The cost of handling grain is rather hard to figure. A plant may not handle the same amount of grain two years in succession. It may also be stated that, while the characteristics of these elevators as to major details are identical, the conditions under which they operate are at a variance.

It has been shown in Table I, that a certain plant handles $20,000,000 \mathrm{bu}$. of grain on 1500 tons of coal at $\$ 4.00$ per ton. Including the operating costs, the cost per bushel over a number of years was shown to be 0.057 cent per bu.

Another plant handled for one year, $30,000,000 \mathrm{bu}$. of grain on $675 \mathrm{kw}$. at a maximum demand charge of $\$ 10,492.44$ on a basis shown at the conclusion of this paper. This brought the cost per bushel down to 0.035 cent per bu. 


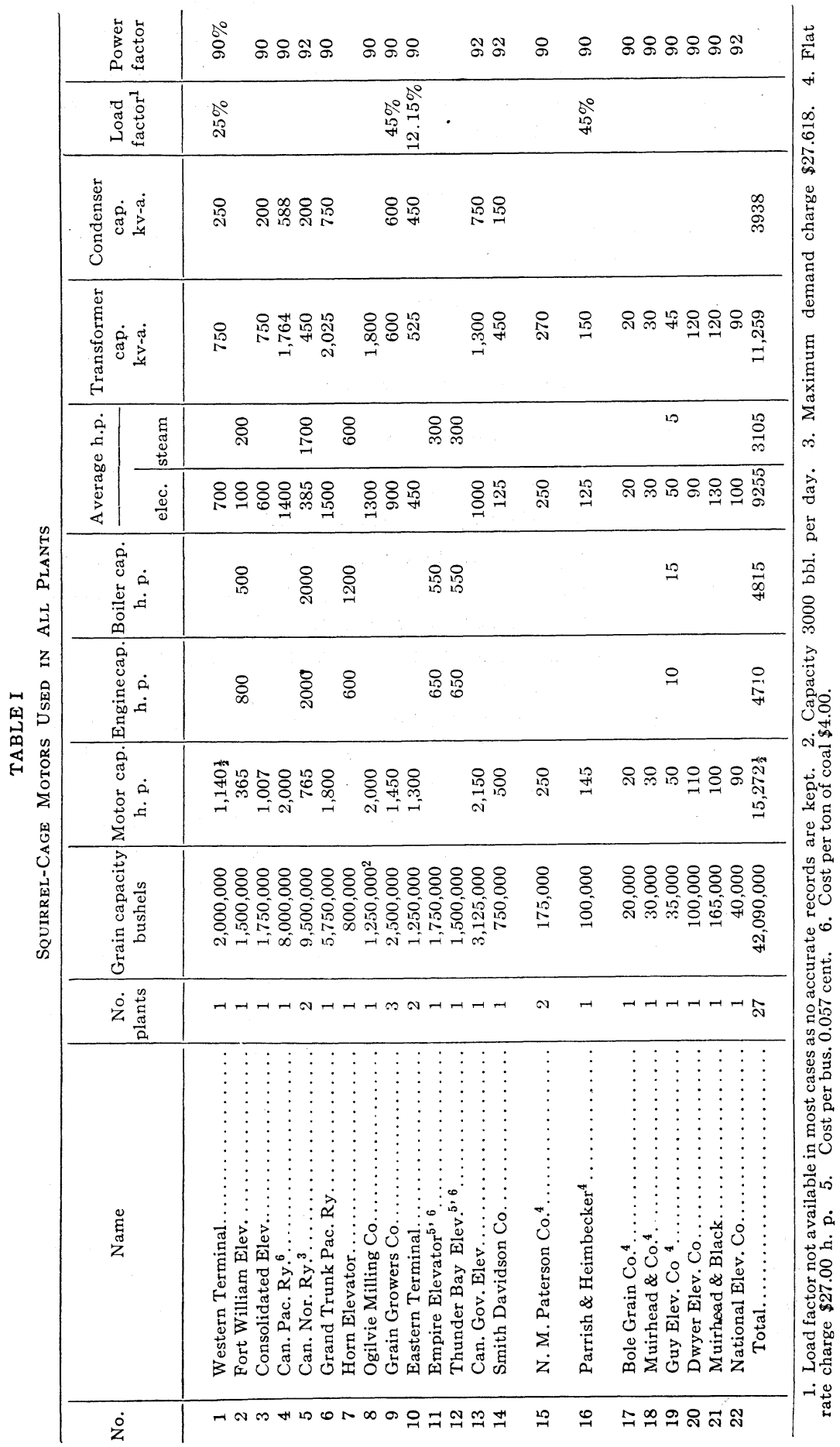




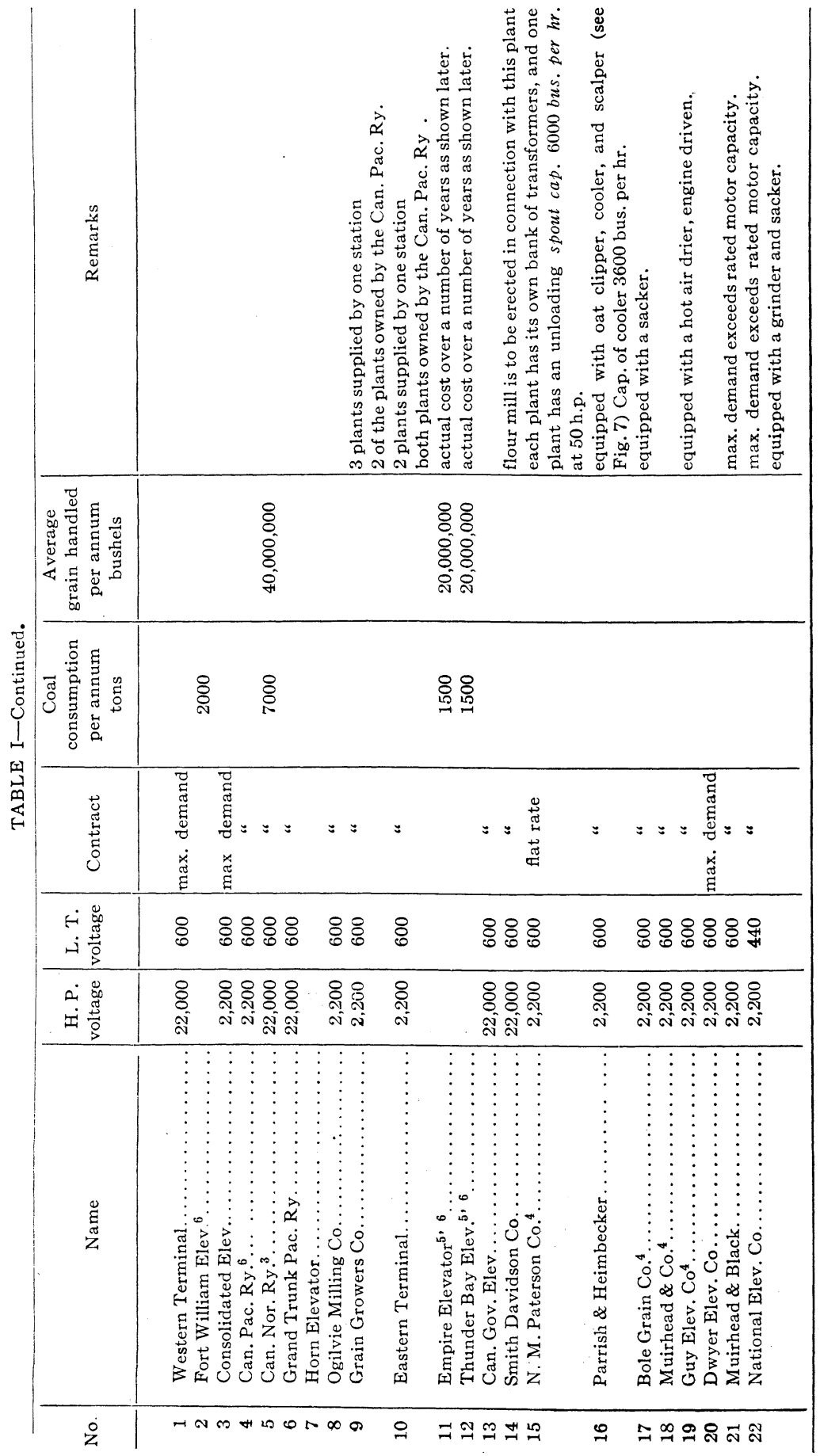


Another plant handled 500,000 bu. on 100 h.p. flat rate at $\$ 25$ per h.p. or 0.05 cent per bu.

From Table I, item 5, it will be seen that this plant handled $40,000,000 \mathrm{bu}$. on 7000 tons of coal, which, with the opera. ting expenses, brought the price to 0.042 cent per bu.

As stated before, this information, while authentic for the period mentioned, can hardly be called an average.

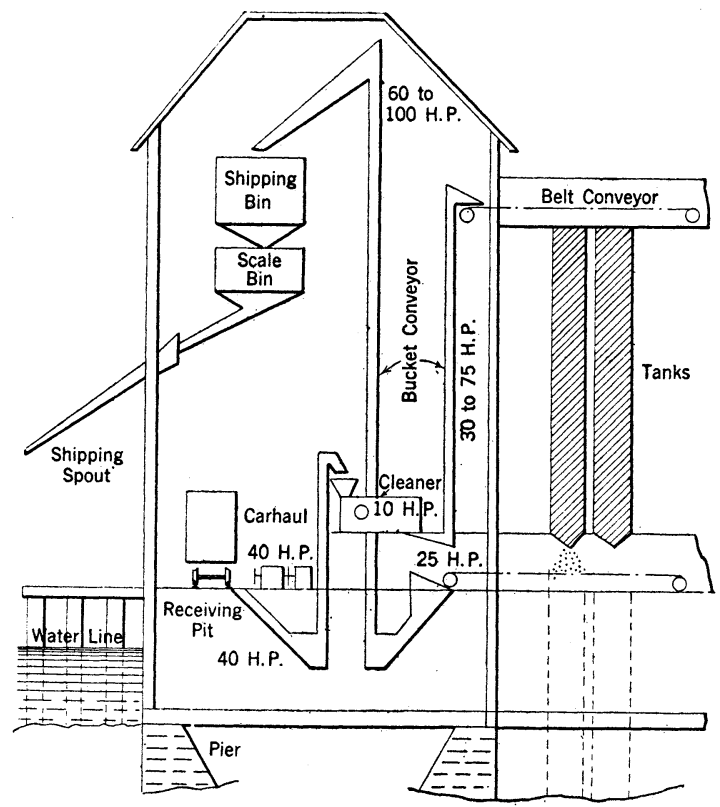

Fig. 6-Diagram of Grain Elevator

\section{Handling the Grain in Elevators}

The handling of the grain may be grouped under a number of headings such as:

1. Receiving; car haul, unloading.

2. Cleaning.

3. Conveying; storage tanks.

4. Conveying; hopper conveyer.

5. Weighing; shipping.

6. Drying.

Car Haul. The cars are shunted into the elevator by a yard engine, after which they are moved by a cable drum over the receiving pits. The size of the motors for the car haul depends on the capacity of the elevator and the average number of cars 
handled at one unloading. For a train of 25 cars a 40-h.p. motor is used.

The motor starts under no load and the load is gradually thrown on by a friction clutch attached to a cable drum. The strain is sometimes very great as for a train of 25 cars a 40 -h.p. motor would exert itself 40 to 60 per cent above rated capacity. As this is only for a few seconds, the load as a whole is of little importance.

Unloading. The grain is shoveled from the cars by reverse cable shovels; generally two to a car, each operated by one man. Of course the greater part of the grain leaves the car by gravity as soon as the grain doors are removed, and the shovels are used for the remote corners and floor. It usually takes $30 \mathrm{~min}$. to unload a car containing $1100 \mathrm{bu}$., 66,000 $\mathrm{lb}$. Each receiving pit has a set of two shovels. The power required to operate two shovels is approximately 7.5 h.p. The

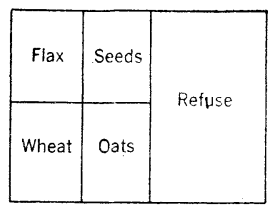

Fig. 7-SCALPER

This consists of five sieves, with a spout leading from each compartment to conveyers. load is intermittent and very seldom exceeds the normal capacity of the motor.

Cleaning. While the grain does not necessarily go through the cleaning process immediately after it is removed from the cars, this subject will be treated first. From the receiving pits, the grain is carried by bucket conveyers either to the cleaner or storage tanks, as the case may be. The cleaners are located on the first "deck" of the elevator. At the cleaner the grain is separated from the chaff, dirt, etc. The screenings (false grain and others) are transferred to a bin where they are afterward sold for feed. The chaff is drawn by suction into a blower and carried to the boilers direct. The foul seed is taken to a bin where it is afterward disposed of. The power required for the blower is from 15 h.p. for a $2,000,000$-bu. plant, to 75 h.p. for a $9,000,000-$ bu. plant. The load is constant and never exceeds the full load rating. The motors for the cleaners range up to 10 h.p. and are never overloaded. The load is practically constant.

Conveying and Storage Tanks. The good grain is taken by a bucket conveyer from the cleaners to the tops of the tanks, where it is dumped on a belt conveyer, to be distributed to the various tanks. The tanks are constructed, as before stated, of steel, tile or concrete. A belt conveyer runs between two sets of tanks and the grain is shunted into the proper tank by means of a "dumper." This dumper consists of a set of rolls, between 
which the belt passes, on the same principle as a belt tightener. By closing the dumper the grain is diverted to a chute and then into the tank. The dumper is mounted on rails and is generally moved by hand.

The bucket conveyers require from 50 to 75 h.p. motor capacity, according to the height of the conveyer and the size of the buckets. These motors start under light load, but as soon as the grain starts the motor is loaded to its normal capacity. The belt conveyers probably have the heaviest conditions to work under, having to start under great stress, sometimes double their rated motor capacity, and in many instances the autostarters are of no use whatever, the handle having to be thrown to the running position to start. It is not an uncommon occurrence for a 15-h.p. motor to blow a 100-ampere fuse, or five times normal load. The load is also intermittent owing to opening and closing of the hoppers, necessary in mixing grades of grain.

In warm weather these motors work at about 75 per cent full capacity, while in cold weather they work as high as 20 per cent above rated capacity, due to the effect of the temperature on shafting, journals, belting, etc. In connection with these motors, the question might be asked, "why are not larger motors used?" In the first place the extra cost is to be considered, while in the second place the season for grain handling is generally from the opening of navigation on the Great Lakes until the closing, that is, from the 15th of April until the 5th of Dec., or in temperate weather. The motor capacity for belt conveyers is anywhere from 15 h.p. to 50 h.p., depending on the length of the belt. These belts travel at about 650 feet per minute.

Conveying; Hopper Conveyer. From the tanks the grain is directed through a hopper in the bottom of the tank to another belt conveyer, where it is carried out of a tunnel under the tanks, to a bucket conveyer, where it is carried to the garner bins.

Weighing and Shipping. From the garner the grain goes into the shipping bin, mounted on scales and situated directly beneath it. After it is weighed, it goes to the shipping spout and thence to the hold of the vessel. The capacity of the scale is $60,000 \mathrm{lb}$.

Drying. All grain that is damp has to be dried before shipment. No matter how smutty, damp or dirty it is, it is dried and sold to the miller in that state. The elevator companies 
used to wash the grain, but it was an expensive operation, considering they got no more for it. The washing bleached it and the value decreased accordingly. Now the mills wash the grain and gage the amount of moisture necessary in the milling process. The defective grain is therefore taken direct to the driers and treated. The drier is a bin generally containing 500 bu. of grain, fitted with vertical sieves and an air chamber, as shown in Fig. 8.

The air chamber is in the center surrounded by the sieves. There is a blank space between each sieve as shown in the cut, and the air circulates in the direction of the arrows. Connected to the drier by an air duct, is a 60 -in. fan running at $250 \mathrm{rev}$. per min. There are two types of driers: hot and cold. The

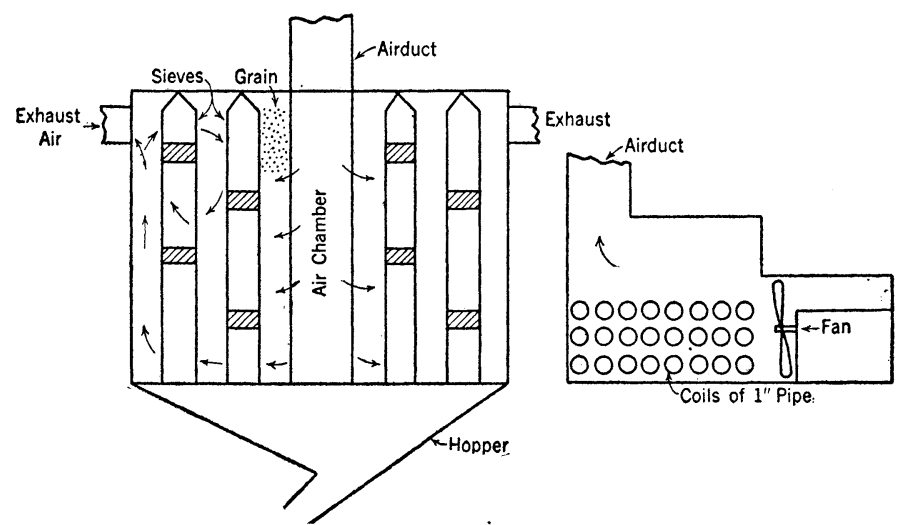

FIG. $8 \mathrm{~A}$

FIG. 8B

heat is generated by steam. Each heater is made up of 6000 feet of one-inch pipe, and the heat is kept at a temperature of 80 deg. cent. A cold air drier is also operated by a fan, taking a good deal longer than the hot air drier. From the driers the grain is taken to the storage tanks.

Period of Shipping. The grain starts to move as soon as navigation opens and continues rather brisk until the bulk of the grain in storage, in the elevators and cars is shipped. This generally takes until the middle of June. The months of July, August and part of September are slack; and the time is taken advantage of to make repairs, in readiness for the fall rush. This generally starts in the latter part of September (crop conditions govern this) and continues to the end of navigation. This is the busiest season of the year and the peak is established 
during this period. It is during this time that elevator companies get the best advantage of the maximum demand, as they run full 24 hours. As was before stated, navigation virtually closes, midnight December 5 th, as the insurance runs out at that time; but a large number of vessel owners carry their own insurance and continue carrying grain until the canals freeze up.

\section{Conclusion}

The day load of an elevator is irregular, especially when the process of unloading cars and loading boats is in progress. Fig. 9 shows a typical day load.

The night load, on the other hand, is practically constant, and is the period taken advantage of. During the night there is very little loading or unloading, and the work done is principally

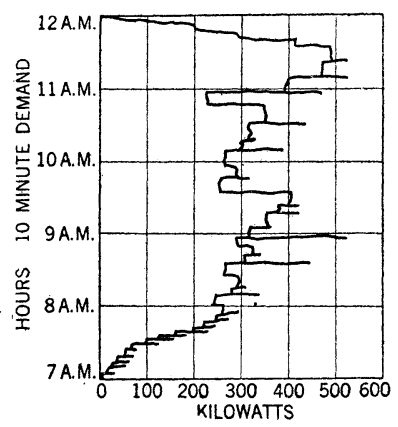

Fig. 9-Typical Day Load First 5 Hours

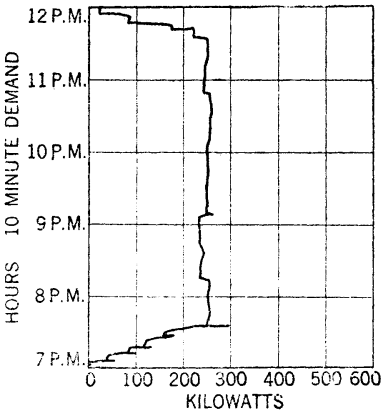

Fig. 10-Typical Night Load First 5 HOURS

cleaning and conveying, the grain traveling in a continual stream. Fig. 10 shows a typical night load.

In Fort William the power facior is maintained at 90 per cent, while in Port Arthur it is 92 per cent.

All the induction motors are squirrel cage type, "protected and self-ventilating." The motors are all protected by fuses and in most cases have a no-voltage release on the auto-starter. As a general rule the motor is either connected to its load by chain or rope drive; a few are belt connected, while a few are geared. The trouble from breakdowns and burn-outs is almost negligible. With the use of vacuum cleaners and compressed air, and the proper care, probably not more than five burn-outs occur in all the plants in one season. The maintenance charges are very small as these plants seldom employ more than two 
operators each. The operators as a general rule receive $\$ 125.00$ and $\$ 90.00$ per month, respectively.

\section{Cost Data of Stations}

The cost per $\mathrm{kv}$-a. for the average $22-\mathrm{kv}$. station, including buildings, transformers, synchronous condensers, high- and lowtension apparatus, is from $\$ 37.777$ (the lowest) to $\$ 42.75$ per $\mathrm{kv}-\mathrm{a}$.

The cost for a 2200 -volt station is from $\$ 35.65$ to 39.72 per $\mathrm{kv}-\mathrm{a}$.

\section{Power Costs}

As before stated the flat rate charges are $\$ 25.00$ per h.p., while the maximum demand is figured on the following basis.

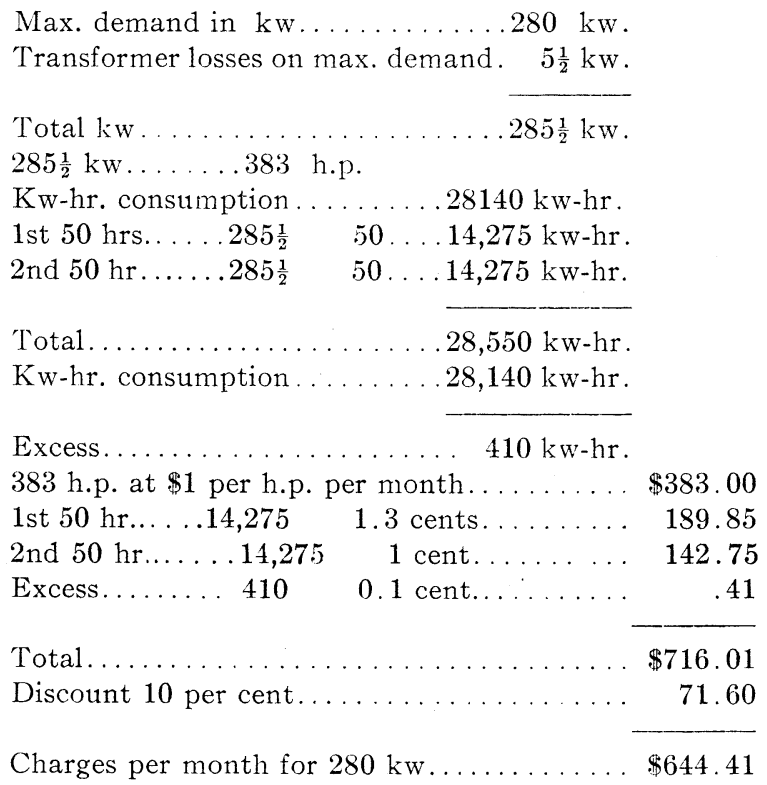

This gives a rate of $\$ 27.618$ per $\mathrm{kw}$. per annum, but as this bill was the first rendered and the average load per annum of 40 per cent lower, it would be very misleading to quote any figure on the actual cost per kw. per annum. 
Discussion on "Fields of Motor Application" (Rushmore), and "Electricity in Grain Elevators" (Stafford), Deer Park, Md., June 29, 1915.

\section{The Electric Elevator}

H. D. James: We often hear engineers speak of the difference in efficiency between electric elevators of the same size, and many of them seem at a loss to understand why this difference exists. It will perhaps be made a little clearer to many of them if we analyze the various sources of loss which occur between the motor and the load, and point out some of the factors which cause a variation in these losses.

The useful work done by the motor is the net load lifted or lowered in the car. In order to equalize the work done by the

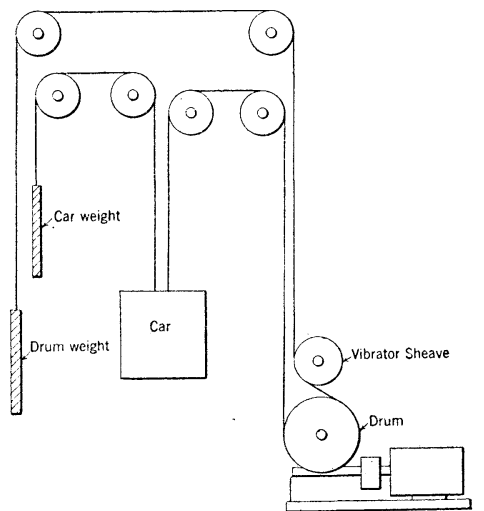

Fig. 1-Common Arrangement Having Six Overhead Sheaves and One Vibrator Sheave

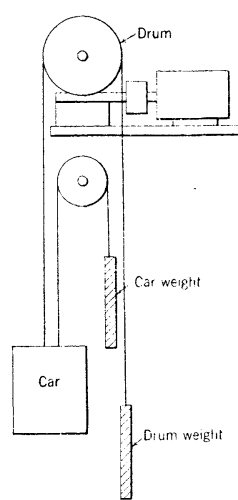

Fig. 2-Best Arrangement Having One Overhead Sheave and No Vibrator Sheave

motor, it is customary to use a counterbalance which is equal to the weight of the car and the average load combined. Sometimes this counterweight is split in two parts, one part known as the car weight, is attached directly to the car, and is less than the weight of the car. The other weight known as the drum weight is attached to the drum and is equivalent to the unbalanced car weight and the average load. The drum weight is wound up on the drum as the car rope is unwound, and vica versa. For smaller installations, the car weight is omitted and all of the counter-balance is attached to the drum. Figs. 1 and 2 show this in diagram form.

The car and counterweights travel on guide rails attached to the sides of the elevator shaft. The top and bottom counterweights in each frame are usually slotted in the ends and extend 
around the guide rails. Considerable clearance is allowed and if the weights are properly hung, there is very little pressure on the rails.

The elevator car is usually hung in a steel frame called a girdle. This girdle is provided with top and bottom guide shoes. These shoes are usually adjustable for clearance and are held against the guide rails by springs so as to reduce the vibration of the car. The car is frequently loaded off of center so that at times there is considerable pressure between the guide shoes and the rails. The friction loss between these guide shoes and rails is affected by the material used, the lubrication and clearance of the shoes. The construction of the rails and particularly the joints, may have a considerable bearing on this friction. In well constructed elevators, the total loss from this source can be made quite low, although some cheap elevators using a poor grade of rails, may have considerable loss.

The ropes are usually led over several sheaves before they reach the drum or counterweight. The arrangement of the ropes and sheaves may be a large factor in the total losses. Fig. 1 shows a common arrangement having six sheaves in the overhead work and one vibrating sheave just above the drum. This sheave, in addition to revolving, is allowed to travel horizontally on the shaft, so that it will be directly above the groove in the drum on which the rope is wound. As the rope winds on the drum, it travels back and forth across the face of the drum. Sometimes it is necessary to set the elevator back from the shaft and use two vibrating sheaves, one for the car ropes and one for the drum weight ropes. It will be evident to any engineer that the friction depends upon the number of sheaves, it also depends upon the load on the bearing of the sheave. There is a further loss due to the bending of the rope as it changes from a straight line to a curve in passing over the sheave, and again, as it changes from the curve to a straight line on leaving the sheave. This loss is proportional to the diameter of the rope divided by the diameter of the sheave. For this reason, large sheaves should be used wherever possible.

The arrangement shown in Fig. 2 is sometimes possible and when used, gives the least sheave and rope friction. If the car weight is omitted in the Fig. 2 arrangement, we do away entirely with sheave loss and the only rope loss will be due to the bending around the drum.

Occasionally the rope is led around sheaves so as to bend the rope back on itself something in the form of the letter $\mathrm{S}$. This gives a considerable bending friction on the rope, and, in addition, is very bad for the rope as it causes excessive wear.

With a careful arrangement of sheaves and by using large diameters, these losses can be kept down to a comparatively small value, but it can be readily seen that these losses may be considerable with a poor arrangement.

We have now traced the losses from the car and counterweight 
back to the winding machine. The winding drum is usually driven by worm gearing immersed in an oil bath. There are a number of systems for cutting this worm gearing. The angle of the worm may also be varied over a considerable range. We can have a single, double, or triple threaded worm. Uusally the greater the angle of the worm, the greater the efficiency. It is, however, the practise of elevator builders to keep this angle small so that the car will not overhaul from rest.

It is very necessary that the worm and worm wheel be accurately machined, and with some systems of gearing, the worm must be very accurately adjusted for meshing with the worm wheel. There seems to be a prevailing idea that the continual wear of the two elements will reduce the friction and improve the efficiency. This is only true to the extent that roughness due to machining may be worn off and the surfaces polished. If the gearing is not correctly cut, the wearing away of part of the material is very unlikely to shape the teeth in the proper way. This is as true of spur gearing as it is of worm gearing and it is a well known fact to those who have made a study of the subject.

The worm exerts an end thrust unless two interlocking worm gears are used. This thrust on the single worm gear must be taken up on a thrust collar, which is often ball bearing or roller bearing; it may, however, be hardened steel disks or bronze disks, depending upon the design of the machinery. The difference in friction between a good ball bearing end thrust and an ordinary disk end thrust is considerable.

Lubrication forms a very important element in the gearing. If the oil is too thin, or is not properly applied, the gears will cut. If the lubricant is too viscous, it causes a loss due to the added effort required to turn the worm. The material from which the worm and worm wheel is made will make considerable difference in the friction.

Manufacturers usually operate the worm gearing before shipment sufficiently to rub off the tool marks and get it in good condition, so that the elevator gearing at the time of installation, should operate near its maximum efficiency.

In selecting a motor to drive an elevator, we must first know the net weight to be lifted and the speed at which it is to be lifted. This gives us the h. p. expended at the load. The total efficiency of the machine is then approximated and the rating of the motor determined. The speed of the motor operating at the above load will be the full load speed of the motor. Some designs of motors have a considerable variation in speed between no load and full load, so that the no load speed of the motor should not be used; this is particularly true of squirrel cage induction motors. The ratio of motor revolutions at full load to drum revolutions is the gear ratio. This fixes the number of teeth in the worm wheel and diameter of drum. Where double or triple threaded worms are used, one-half or one-third of the total number of 
teeth in the worm wheel should be taken in figuring the gear ratio.

When the elevator car is at rest, it will require about double the running torque to start the load from rest, as the static friction is about double the running friction. The power required to accelerate the load can be neglected unless the speed of the car is high, such as 500 or $600 \mathrm{ft}$. per min. For low-speed passenger and freight service, the limiting characteristic of the motor is usually the starting torque; the motor being in service for such a small percentage of the time that the heating is not an important feature. The motor that will start the load with the least amount of current from the line is the desirable motor. This desirable starting characteristic is usually obtained at the sacrifice of efficiency and regulation. For higher speed service, these last two considerations cannot be neglected.

Efficiency is not an important item where the operating is infrequent and regulation is not important for low car speeds. In considering speed regulation, it must be remembered that the motor may act as a generator in lowering the load and, therefore, the difference in speed of going down with full load and going up with full load, will depend entirely upon the regulation of the motor. With a car speed of $300 \mathrm{ft}$. per min. much closer speed regulation is necessary than with a car speed of $100 \mathrm{ft}$. per min.

The d-c. elevator motor is usually compound wound and the controller is arranged to short circuit the series field winding when the motor reaches full speed. With this type of motor, the speed regulation is very good. The same may be said of the adjustable speed motor which is shunt wound and has a speed variation due to change in the strength of the shunt field winding. The question of regulation seldom becomes important with the d-c. motor when used in connection with a geared machine. Where this motor is used on a direct traction elevator running at 500 or $600 \mathrm{ft}$. per min., the regulation is one of the controlling features of the design.

For a-c. power, the choice between squirrel cage and slip ring motors is often one of regulation. Either motor can be given good starting characteristics by designing the secondary circuit with the proper amount of resistance. The squirrel cage motor must operate at full speed with this same resistance, so that it has a considerable slip often as high as 20 or 30 per cent. The slip ring motor is provided with a controller for short circuiting the secondary resistance during acceleration, so that the slip at full load may be as low as 3 per cent or 4 per cent. The squirrel cage motor is preferable on account of the simplicity of the controller, but it is limited to low-speed elevator work on account of this large variation in speed.

On account of the secondary resistance of the squirrel cage motor, the full load speed is less and the gear ratio between the motor and the drum must be higher than for the slip ring motor having the same number of poles, in order to give the same car 
speed. This means that for a given h. p. motor with equal number of poles, the slip ring motor will not be required to develop as much torque as the squirrel cage motor. The squirrel cage motor, however, gives a better torque per ampere input than the slip ring motor on account of the design characteristics. These two conditions about balance each other so that with a properly selected motor and correct gearing, the same load can be started with about the same ampere input to the motor. This analysis is very important as we frequently hear advocates of one motor or the other claim superiority in starting characteristics. Usually the actual results are obscured by the use of improper gearing or by variations in the total efficiency between the motor and the car. It is necessary for elevator builders to have a limited number of gears for each size of machine and the architect is often restricted in his design of the building so that the elevator cannot always be installed for the maximum efficiency. There is also difference in workmanship and materials used so that it is not fair to compare two installations without having analyzed all of the facts.

The problem of stopping an elevator car is much more serious than that of acceleration. The motor may be acting either as a motor or as a generator, depending upon the direction and amount of the load. When the car reaches the top and bottom floors, it is necessary to stop the elevator automatically so that an accident will not occur due to the carelessness of the operator. The distance the car can travel beyond these floors is called the overtravel and is usually very limited. With low-speed elevators it is not difficult to stop the car as the energy required is proportional to the square of the speed. When the d-c. motor is used, a fixed low speed can be obtained by strengthening the field of the motor and by placing a shunt resistance around the armature. The motor is also used as a generator for dynamic braking in bringing the load to rest. This enables the engineer to apply the d-c. motor to high-speed elevator service with excellent results. The d-c. elevator has been used for the longest travel elevators installed, operated at the highest speeds; in fact, there are installations where only an electric elevator could be used.

The use of an a-c. motor for high-speed elevator service has presented a difficult problem. The motor as usually built, has only one fixed speed. The car must, therefore, be brought to rest by the mechanical brake from the maximum speed. This places a limit upon the speed of the elevator. Elevators of this kind are usually limited to $200 \mathrm{ft}$. per min., although higher speeds have been used in some instances. Recently, some induction motors have been built having two sets of poles in the primary; one set of poles for full speed and one set of poles giving one-third speed. The secondary also has two sets of windings. This enables the engineer to arrange for a fixed low speed from which to make his stops and has materially increased the limit 
of car speed for which an induction motor-driven elevator can be used.

To summarize: The total efficiency of electric elevators may vary over a considerable range, from as low as 25 per cent to over 75 per cent, depending upon the design, workmanship and arrangement in the building. The losses may be separated under the following headings:

1. Friction of car and counterweight on guide rails.

2. Bearing friction of sheaves.

3 . Bending friction of ropes.

4. Efficiency of worm gearing.

5 . Efficiency of electric motor.

Item 5 affects the power bill only and is not important where the operation is infrequent. Items 1 to 4 , inclusive, influence the size of motor used as well as the power bill. It is to the advantage of the purchaser to keep down the size of his motor. A large motor is less efficient on average loads, and increases the strain on the machinery and the first cost of the elevator.

\section{Individual Motor Drive as Used in the Oil Flotation Process}

W. M. Hoen: One of the most important of the latest applications of motor drive as applied to the metal mining industry is found in the oil flotation process. There are several variations of the flotation process in use, but this application refers specifically to the mechanically agitated type as used in copper and zinc mining.

In the treatment of copper ores the solutions are generally worked cold, while in treating zinc ores it is found advisable to work the solutions hot. Due to the violent agitation the air above the tank is always filled with a very fine spray. In mills using the hot solution method the air is heavily laden with moisture, unless removed by fans.

The tanks or cell boxes are approximately 2 by 3 feet and are assembled in groups of from 8 to 16 , depending upon the class of ore being treated. During the development of the process crossed belts constituted the original method of drive. They were successful for the small experimental machines but when applied to commercial work were not satisfactory. In the zinc mills, due to the excessive moisture, they were found to be an absolute failure. The next step was to use a bevel gear driving each cell of the unit from a common shaft. In practise this method was partially successful but a great many difficulties were at first encountered. The friction losses were high until cut gears were used, which were completely enclosed so as to run in oil. The thrust caused by the weight of the gears, shafting and propeller caused considerable trouble. Any slight difficulty with one unit which would cause a shut-down, reduced the mill tonnage by an amount equal to the output of the total group of cells. Expensive thrust collars of the ball bearing type were some- 
times used in order to improve the mechanical operation. About the end of 1913 this process was so well advanced that the mill operators decided that a more efficient and flexible system of drive was advisable.

Practically all of the agitators in successful operation were running at a speed of $265 \mathrm{rev}$. per min. The application of vertical motors, one to each tank, appeared to be the best solution. However, practically all of the metal mines in the West have 60-cycle power, so that a direct-connected motor to run at this speed is almost an impossibility, from a design and commercial standpoint. The original process started out with an agitator running at about 3 rev. per min. Development had brought this speed up to $265 \mathrm{rev}$. per min. and the only apparent reason for this definite speed was that with the design of propeller in use the most efficient results were obtained at this speed. Experiment had shown that each tank would require between 7 and 10 h.p. A three-phase induction motor built for this rating at 60 cycles does not give good performance nor reasonable manufacturing costs if built for more than 12 poles. It was decided that a 12-pole motor of the vertical type would be the best proposition as standard parts would be available. This meant that the agitator must run at a speed of $570 \mathrm{rev}$. per min. The problem now was for the metallurgists to devise an agitator cell and propeller which would give the desired results at this speed. These results were very successful and this speed has now become practically standard.

The motor as finally applied consisted of standard vertical parts with a special sub-base and bearing. This sub-base was designed in conjunction with the agitator cell. The lower bearing was practically a standard although of extra large size. The shaft is threaded so as to take a screw coupling and the propeller is mounted on a short piece of shaft which is coupled to the motor shaft and prevented from locking by a small block. This makes a very strong, compact and simple construction so that an additional bearing is not required. The vertical bearing must be capable of supporting the additional weight of the propeller, its shaft, and a downward thrust due to the action of the propeller. The excessive moisture condition made it advisable not to permit circulation of the air from the top of the tanks up through the motor windings. This was prevented by providing an enclosing plate in the sub-base. In a motor of this rating and number of poles, its over-all size is such that nearly all of the heat due to the losses is given up by radiation and not by convection. In order to prevent injury to the windings during periods of idleness it was necessary to impregnate them with a moisture-resisting varnish. Each bearing is lubricated independently; the oil inlet pipe for the lower bearing is cored in the base. A pipe, as ordinarily used, would be quickly destroyed by action of the metallic particles.

The design of agitator cell and propeller finally adopted requires 10 h.p. when operating under normal condition. A 
change of metallurgical conditions will cause this to vary from 7 to as high as 20 h.p. However, it was found that with these changes in h.p. the metallurgical results also varied. The most desirable range was found to be such, that a motor with a normal rating of 10 h.p. would have to carry 25 per cent overload continuously and 50 per cent overload for short periods without reaching dangerous temperatures. This overload condition only applies to the motors in the series which do the preliminary mixing. Some cells are grouped for rougher service, separating the higher values, the tailings being reground and treated in the finisher cells which give the finished product. However, no appreciable saving could be effected by making the motors of different capacity, as any saving would be offset by the advantages of having all motors duplicates.

This process has taken great strides in the last year and a half, so that several hundred agitator cells are in operation. At first sight it might seem that the application of individual motors is a very expensive method. Some of the most important advantages are as follows:

(1) Each cell is a unit so that one cell may be shut down with only a relatively small reduction in mill tonnage.

(2) Mechanical difficulties due to gears, many bearings, shaft alignment and the hazard from belts is entirely removed.

(3) The operation of each cell can be easily checked by the power consumption.

(4) In the majority of these plants the cost of power is the smallest item, continuity of service and reliability of operation are of the greatest importance. In metal mining the use of any particular method of drive or type of apparatus is simply a means to the end, as the object of the mine and mill is to produce metal.

(5) The results obtained from the metallurgical end are such a great improvement over the water concentrating methods that the total mill equipment required is actually less and the labor required to handle a given tonnage is reduced. Although this process is now being used chiefly to recover values from slimes, which values were formerly lost, there are indications that it will be used for the total recovery of certain classes of ores.

The unit drive has proven very successful and shows what success can be obtained by the close cooperation of the electrical and metallurgical engineers in solving an apparently simple but complex power drive.

\section{Fractional Horse Power Motor Application}

H. F. Boe: Small motor applications fall into four classes depending upon the operating period and the variations in load.

1. Continuously operating motors with approximately constant load.

2. Continuously operating motors with varying load.

3 . Intermittently operating motors with approximately constant load.

4. Intermittently operating motors with varying load. 
It is usually impossible to obtain data by correspondence sufficiently accurate and complete to permit an engineer to calculate a suitable motor to drive a certain machine or device, on account of the peculiar characteristics of the machines themselves as well as the extreme variations in operating conditions while in service.

Most small motor-driven machines are manufactured in quantities sufficiently large to warrant careful tests to determine the application. A sample motor with electrical characteristics approximately those required is generally used to analyze the application.

Owing to the policies followed by central stations, 110 -volt, 60 -cycle lighting circuits are nearly universal and motors of the split-phase type are used to a considerably larger extent than any other type of small motor. This type of motor is generally used for test purposes.

Tests. The main readings to be taken on test are:

1. Volts.

2. Amperes.

3. Watts.

4. Speed of motor.

5. Speed of machine.

These should be made for each of several loads, enough readings being taken to represent all actual operating conditions.

A very careful analysis should be made of:

1. Starting condition

2. Normal and maximum load conditions.

3. Cycle of operation.

4. Length of operating period.

5. Method of drive.

6. Peculiar mechanical or electrical characteristics required.

Starting Torque. The torque required to start the machine under normal and maximum load conditions must be definitely determined. This can be obtained by reducing the voltage at the motor terminals to a value just sufficient to start the machine and bring it up to speed. By substituting a Prony brake and a scale for the load and measuring the locked torque of the motor at the voltage obtained above, the actual starting torque is obtained. This is usually expressed in ounces at one-foot radius.

Normal and Maximum Torque. The normal load torque can be obtained by means of a brake test on the motor at the same input found under actual operation of the machine at normal load. The maximum torque can be determined in the same way if the maximum load is of sufficient duration to read the motor input. If this is not the case it can be obtained by reducing the voltage at the motor terminals to a value just sufficient to carry the maximum peak load. By substituting the Prony brake for the load and measuring the pull-out torque of the motor at the reduced voltage obtained above, the actual maximum torque is determined and is expressed in the same terms as the starting torque. 


\section{Temperature}

The temperature rise of the motor for normal operating load should be determined by actual test and the overload conditions and the possible temperature rise under overload taken into consideration. Where feasible these heat runs should be made in connection with the driven machine, since this method more nearly gives the actual operating temperature. However, where this is not feasible, temperature test on the motor may be taken in some more convenient way and still approach operating conditions.

\section{Methods of Drive}

The method of drive determines largely the speed of the motor selected and likewise the mechanical characteristics of the frame, brackets, shaft and bearings, and therefore is of vital importance in the application of the fractional horse power motor.

Belt. Where round or flat belts are used the ratio of pulleys should be such that the motor pulley will be of normal size. The distance between pulley centers should be great enough to eliminate excessive belt tension, or if this is impossible an idler pulley should be used. Small motor pulleys and short belt centers are sometimes used successfully on very small machines where the load and starting conditions are comparatively light, but ordinarily idler pulleys are desirable where the pulley ratio is large and the distance between the belt centers small.

Spur Gears. Numerous small motors are connected to the driven devices by means of spur gears. This gives a very positive drive and excellent results are obtained. In general, it is desirable to keep the gear ratio 5 to 1 or less, but some small motor driven machines use successfully gear ratios considerably in excess of this. A careful analysis should be made of limiting pinion sizes before gear ratios exceeding the above are used.

Bevel Gears. If the motor drives the machine through bevel gears the best results on small machines seem to be obtained where a ratio of 2 to 1 is not exceeded. However, in some cases ratios as high as 3.5 to 1 have been used successfully, depending on method used in manufacturing gears. This drive is positive, but there is always some end thrust which must be taken care of in a way which will not cause undue wear on the motor bearings.

Silent Chain. If large reductions in speed and only a short space between motor shaft and machine shaft is available, a silent chain drive may work admirably, since large ratios of sprockets and short chain centers are permissible. This makes a very good positive drive.

Worm Gear. Worm gear drive is used extensively and large reductions in speed are obtained. Where this drive is encountered care should be taken to see that the worm thrust is properly taken care of. In general, the worm should have its own thrust bearings which must be large enough to take a thrust equal to the maximum torque of the motor. 
Friction. Where friction drive is used careful measurements of the thrust on the motor shaft should be made. If any thrust is found it may be necessary to equip the motor with special thrust bearings. This method of drive is used largely where it is desirable to get an adjustable speed with a constant speed motor; for example, moving picture projecting machines.

Direct Connection. When motors are to be directly connected to the load the method of mounting should be noted. The distance between center line of shaft and base should be determined and the amount of permissible variation specified. The distance from center line of motor to end of shaft extension, the length and diameter of the shaft extension and whether the motor has to take care of end thrust must also be investigated. This method of drive is being used with excellent results. Sometimes rigid couplings are used, but in general, flexible couplings are more desirable.

\section{Mounting}

A careful analysis should be made of:

1. Method of drive.

2. Method of mounting-Is motor to be arranged for floor, wall, ceiling or vertical suspension?

3 . Location of the motor with respect to machine it drives.

4. Limiting space available for the motor.

5. Limiting manufacturing dimensions in regard to distance from center line of shaft to base, and center line of motor to end of shaft extension.

\section{Choice of Motor}

$A-C$. Single-Phase. Having determined the mechanical and electrical characteristics of the motor required to drive successfully the machine in question, there are various other features to be taken into consideration before definitely recommending a motor.

An allowance must be made for:

1. Variations incident to manufacture of machines in quantity.

2. Variations incident to manufacture of motors in quantity.

3. Minor variations in voltage.

4. Minor variations in frequency.

Since the torque of a motor at starting varies approximately as the square of the voltage, it is imperative that a motor be selected that will start against the worst possible conditions. This is due to the fact that they are generally connected to lighting circuits where insufficient transformer capacity or light wiring will cause the voltage to drop considerably at times, particularly when starting. This voltage may be reduced to possibly 80 per cent of its rated value, the starting torque of the motor then being approximately only 64 per cent of the torque at full voltage.

The maximum torque of the motor selected must be sufficient for the worst load condition to which the machine will probably 
be subjected at a voltage at least 10 per cent below normal rated voltage.

The motor should be capable of operating on a circuit with a variation of 10 per cent plus or minus in frequency, 10 per cent plus or minus in voltage, or an equivalent combination of voltage and frequency.

No-Clutch Motors. Under light load starting conditions and where the motor runs for long periods of time at constant load, motors without clutches should be used. Motors rated $\frac{1}{6} \mathrm{~h}$. p. and below are usually built without clutches, since reasonable starting torques are obtained without objectionable starting current.

Clutch Motors. Clutch motors are designed so that when starting, the rotor revolves freely on the shaft. When nearly full load speed is reached the clutch operates automatically by centrifugal force and engages the shaft through the clutch. With a properly designed clutch the load is then accelerated smoothly and without shock. This type of motor develops practically maximum torque at starting and requires starting current which is less and also of shorter duration than in the no-clutch motors. (See Fig. 2, Mr. Lester's paper.)* It is desirable to use clutch motors where high starting torque is required and particularly so when high starting current is objectionable.

Repulsion Induction Motors. Repulsion induction motors should be applied where the initial starting torque required is very high and the torque drops off very rapidly during acceleration. At the instant of changeover from repulsion to induction running the torque does not exceed a small fraction over full load torque. A typical application of this motor would be a deep well pump. (See Fig. 1, Mr. Lester's article.)*

Odd Frequency Motors. Having selected a suitable 60-cycle motor, it may be necessary to line up suitable motors to operate the machine on other frequencies from 25 to 133 cycles since lighting circuits of other frequencies are sometimes encountered. If these motors are to drive the machine at the same speed as the 60 -cycle motor and proper gear or pulley ratios are made to take care of the variations in speed of the odd frequency motors, it is necessary to furnish proportionate torques on these machines. If it is the intention to use the same pulleys or gears, the motors will have to have the same torques as the 60 -cycle, which in some cases will increase the horse power while in others it will decrease the horse power of the motor, depending upon the number of poles and the frequency of the motor.

$D$-C. Motors. Having obtained the characteristics of the a-c. motors the d-c. motor should be selected having as nearly the same mechanical characteristics as possible.

Shunt-Wound Motors. If the motor starts with light load and runs at practically constant speed with constant or variable load, a shunt-wound motor should be used.

*Page 681 , this volume. 
Compound-Wound Motors. If high starting or maximum torque is required and a slight variation in speed with variations in load is permissible, compound-wound motors should be used. Usually motors below $\frac{1}{8}$-h.p. can be supplied shunt-wound.

Series-Wound Motors. Where exceptionally high starting torque is required, where the load is constant or where a large variation in speed with a small variation in load is permissible, series-wound motors should be used. Series-wound motors, however, should always be connected to the load through a positive drive.

Universal Motors. The so-called universal motors are designed to run on either alternating or direct current and have series motor characteristics. These motors are high speed and used almost exclusively on portable electric drills and small fan type vacuum cleaners.

Open or Enclosed Motors. If motors are to be used in a damp or dirty place, where they may be subjected to water, acid fumes, or where they are in close proximity to inflammable material, they should preferably be enclosed. It is desirable to mount all motors where they get the maximum amount of ventilation.

\section{Printing Presses}

Wm. C. Yates: In the printing industry, the electric motor finds a most important field of application. In fact, the motor is indispensable, as it furnishes the ideal drive for the various machines in a printing plant which in no modern establishment or one of any consequence are operated by any other means. The chief factors favoring motor drive as compared to any other driving means are:

No obstruction to light by overhead belting and shafting.

Cleanliness.

Quietness.

Convenience of location.

Saving of floor space and headroom.

Economy of power.

Wide range of speeds.

Convenient control.

Protection to the operator.

Economy of time-Reliability.

These factors may be recognized as applying to almost any kind of machinery equipped with individual motor drive. There are no machines, however, to which the speed range, convenience of control, and reliability of the electric motor are of greater importance than to a printing press, especially one producing a daily newspaper.

In the general book, pamphlet and job printing industry motors are applied to composing machines, printing presses, folders, cutters, stitchers, and binding machinery. In newspaper printing plants, motors are used on composing machines, matrix and plate making machines, printing presses, paper 
hoists and conveyers and exhaust fans. For all machines with the exception of the presses and folders the selection of a suitable motor is a relatively simple matter and no special features of control are involved. For the most part, constant speed motors are employed and the control may be an ordinary hand starter or in cases where remote control is desired, a self starter may be used which is operated from one or more push button stations. Where the work necessitates the use of an adjustable speed motor, a manually operated speed controller will usually answer the purpose.

The advantageous characteristics offered by the electric motor apply to all the power driven machinery in the printing plant but especially to the presses, which require features of drive and control that nothing else can offer. In the following are taken up the several broad classes of printing presses, with a brief discussion of the types of motors applicable in general to each class and of the features entering into the proper control of the motors.

The various types of printing presses fall into three general classes:

Small platen presses, ordinarily called job presses.

Flatbed cylinder presses.

Rotary presses.

Job Presses. These, used for printing cards, circulars, small jobbing and commercial work, have a type bed and impression platen which are both flat surfaces. The type form is held stationary, and approximately vertical, while the platen on which the paper is placed swings up to meet it. Hand sheet feed is the rule, though automatic feeds are sometimes used.

The general run of job presses require motors ranging in capacity from $\frac{1}{6}$ to $1 \frac{1}{2} \mathrm{~h}$. p. The motors are generally best mounted on the floor and arranged for belt drive to a fairly large press pulley. Friction drive, using a friction pulley bearing against the flywheel, is also used.

The control requirements are simple. On d-c. circuits a shunt motor is employed usually controlled by a no-voltagerelease speed regulating rheostat in the armature circuit. The small sizes of the motors used make permissible control of speed by armature resistance as the wastage of power is inconsiderable, especially as the motors are usually run at or near normal speed.

There are applications, where the speed of production is of prime importance, where a push-button-operated controller, providing predetermined speed setting, gives the best results.

On a-c. circuits the best results are obtained by the use of a commutator type single-phase motor. Such motors are available, designed for speed control by brush shifting and with the shifting mechanism arranged for foot operation.

Flatbed Presses. These have the type forms carried by a heavy, rigid platen sliding back and forth in "ways," similar to the bed of a metal planing machine. At each pass the type 
passes under the impression roll at one end of its travel, and under the inking rolls at the other extreme. There are several classes of flatbed presses differing in the relative motions of the cylinder and platen, although in all types the impression cylinder always revolves in the same direction.

Flatbed presses are employed for sheet printing and are generally used for color work. The feed may be either hand or automatic.

The ideal location for motors is within the frame of the press, on brackets. Belt drive is preferable to gear or chain drive as the slipping of the belt serves as a protection against shocks to the motor and machinery. The motors required range in capacity, for different makes and sizes of presses, from $1 \frac{1}{2}$ to $15 \mathrm{~h}$. p., and must be capable of exerting a strong starting torque, for which reason the d-c. motors are usually compound-wound with about 20 per cent series field. The a-c. motors used are for two or three-phase circuits and are of the slip ring type.

The ordinary requirements of speed variation are met by providing the d-c. motor with 50 per cent reduction by armature resistance, and with field control giving a 25 or 50 per cent speed increase above normal. In the case of the a-c. motor, regulating resistance is furnished which permits of a speed range down to 50 per cent of normal. Ordinarily only the higher speeds are in requisition, the lower speeds being required for occasional jobs where an extra high grade of work is involved.

The ideal control equipment provides for push-button starting and stopping and for predetermined speed control. The ability to start or stop the press from stations at both the feeding and delivery ends makes for greater convenience and safety to the operator and is an important factor in the saving of time. The predetermined speed feature makes possible the proper setting of the ultimate speed for the work in hand so that when the press is producing it will run at that speed. Thus is avoided the wasting of time by reason of running too slow, as also the spoiling of work from running too fast. Furthermore, it becomes possible to work to a definite schedule of production, which is of great importance to the printer.

Other features of the control equipment are:

No-voltage protection to motor and to operator.

Overload protection to the motor.

Dynamic brake or solenoid brake for quick stopping.

"Jogging" or "inching."

Reverse for emergency conditions only.

Recent developments in control equipments for use with a-c. motors incorporate all of these advantageous features. The essential difference is that dynamic braking is, in the nature of things, out of the question, and a solenoid brake is used. The results, however, are identical.

Lithographing Presses. The lithographing press differs from the ordinary flatbed press in that it prints from an engraved 
stone instead of from type. In its various makes and sizes it takes motors ranging in capacity from 2 to $10 \mathrm{~h}$. p. The requirements as to the types of motors, speed range, and control features are the same as for the general run of flatbed presses.

Rotary Presses. Rotary web presses, used largely for magazine or newspaper work, employ curved stereotype, electrotype, or zinc printing plates, attached to the cylinders. They print a continuous roll or web of paper, which allows a much faster speed than even the automatic feed applied to flatbed presses. Due to this feature, and also to the elimination of heavy reciprocating parts, this type of press is superior in point of speed.

Small rotary presses, which may print either on a continuous roll or on automatically fed sheets, are used for work similar to that performed by job presses and flatbed presses. The motors required range in capacity from 2 to 15 h.p. and the types of motors and the control features are essentially the same as for the job and flatbed presses doing similar work.

Rotary Magazine Presses. The sizes of rotary presses used for magazine printing require motors ranging in size from 5 to 35 h.p. The d-c. motors employed are compound-wound and of the adjustable speed type with speed range by field control of $2: 1$, although occasionally a speed range as high as $3: 1$ is of advantage where the work which the press turns out is of widely varied quality. When a-c. motors are used they are of the slip ring type with speed control by resistance in the secondary circuit.

A suitable control equipment may be either "full automatic" or "semi-automatic," although the former is the more convenient to the press operators. By "full automatic" is meant entire control from push-button stations. Each complete master station, of which there may be one or more, contains push-buttons for "jog," "fast," "slow," "stop," and a two-button-operated snap switch for "safe-run." Partial stations, of which there may be several, usually comprise "jog" and "safe-run".

The various contactors and other remotely controlled switching mechanisms actuated by the push buttons are mounted on a panel together with the knife-blade line switches, fuses and whatever instruments may be desired. The panel and resistances connected thereto may be placed in any available space as the complete control of the press is accomplished from the stations and the only devices on the panel ever manually operated are the line switches.

Pressing the "jog" button will cause the press to run at a very low speed as long as the button is held closed. When the button is released the press instantly stops. Pressing the "fast" button will start the press off at the lowest speed and gradually accelerate it toward the highest running speed as long as the button is held down. When the "fast" button is released the press will run at whatever speed it has attained, Pressing the "slow" button causes the press to decrease in speed. The "stop" button 
is used to bring the press to a quick stop. The "safe-run" buttons permit of opening the control circuits at any one station so as to prevent the starting of the press from any other station.

Whether the press be stopped by release of "jog" button or operation of "stop" or "safe" buttons, the brake comes instantly into effect and quickly brings the machinery to rest.

A "semi-automatic" control equipment differs from the "full automatic" in having a manually operated device for bringing the machinery up.to running speeds. The "jog," "stop," and "safe-run" features are, however, controlled by push-buttons exactly as in the "full automatic" equipment.

The equipments for induction motors accomplish much the same results as those for d-c. motors. The advantage in favor of the d-c. motor lies in economical producing speeds over a wide range. When the producing speed is to be at or near synchronous speed the induction motor offers no disadvantage whatever.

Rotary Newspaper Presses. The great advantages of motor drive as compared to any other drive in the case of rotary presses lie in:

Economy of space-Crowded conditions usually prevail in a newspaper plant.

Convenience of control-From several stations and by quickly operated devices.

Safety-All is hurry and bustle and the press operators must be protected against carelessness.

Delicacy of control-The web of paper must be slowly fed in while making ready and gradually accelerated to the full running speed.

Reliability-The loss of an edition is a serious matter.

Some small newspapers are produced by single motor-driven rotary presses in which case the equipment is the same as described for the rotary magazine presses.

The larger newspapers, however, are run off from rotary presses which have a two-motor drive. A small motor is used driving the press through gearing to obtain the make-ready, low speeds. A large motor is used to obtain the high producing speeds. When the large motor takes up the work the small motor is electrically and mechanically, automatically disconnected.

The motors required range in capacity from a $3+25-h . p$. to a $10+100$-h.p. combination. A speed range of $2: 1$ by field and 50 per cent reduction by armature is usually provided in the large motor of the d-c. combination. The running speed range of the induction motor combination is from normal down to about $\frac{1}{3}$ normal. In either case the ordinary producing speed is usually figured at about 75 per cent of the ultimate possible speed in order to allow for contingencies of delay.

The control equipment for the two-motor drive is almost always of the "full automatic" type and the same features of control are incorporated as already described. The push button stations are the same as for single motor drive, but the control 
panel naturally contains a larger array of devices by reason of the fact that both the small and large motor must be controlled and in proper sequence.

A modern newspaper press room equipment may use twomotor a-c. drive. The press may be quadruple or double 16-page unit, capable of printing 30,000 16-page papers or 15,000 32-page papers per hour. Some large newspapers necessitate two, four, six, and even eight press units. Producing speeds vary from 20 , 000 to 36,000 papers per hour, of 12 pages per paper up to 32 pages. Presses even larger and faster have been built.

\section{Motor Applications of the Brick Manufacturing Industry}

T. Z. Simpers: The brick manufacturing industry, including building, paving, ornamental and fire brick, tile, sewer pipe, etc., has an annual production of $\$ 200,000,000$ in value. Approximately 100,000 h.p. is required to make this product, which signifies the importance of the industry from a power application standpoint.

Brick manufacturing plants are located in all parts of the country supplying product for local consumption, and there are few central stations that do not have one or more, either as customers or prospects. The load offered by these plants is attractive to central stations, on account of the fact that during cold weather the brick plant is usually shut down, meaning that the power requirements occur mainly in the summer, when the central station load is otherwise at its lowest point. Owing to the fact that the power requirements for brick plants are small, ranging from 75 to 500 horse power, and consequently the generation of their own power rather costly, power can usually be purchased to good advantage.

The general conditions surrounding the application of motors in brick manufacturing plants are among the worst encountered in any industrial service. These unfavorable conditions are:

1. Severe starting requirements-due to inertia of driven machinery and to material in machinery hardening when at rest.

2. Severe overloads-due to irregular feed of material.

3. Dusty atmosphere about plants and presence of dampness, causing collected dust on the motors to become cemented to the windings, resulting in insulation strains and interference with ventilation.

4. The use of gears of large pitch and high pitch line speeds resulting in severe vibrations.

5. Lack of careful and intelligent inspection of machinery.

Good service is obtained with these conditions only when careful consideration is given to the application of each individual machine. Before deciding on the motor size, type, and method of connection to the clay working machines, it is important to analyze the following points:

1. Starting conditions, including the amount and variation of torque required and the frequency of starting. 
2. Running conditions, including general nature of work to be performed and the variations in load for various rates of production.

3. Mechanical conditions of application.

It is necessary that motors applied in brick manufacturing plants should have-generous starting and running characteristics, bearings dust-proofed, windings impregnated against moisture, The motors should be carefully installed with respect to alignment with driven machines, and drive connecting to same. The requirements vary greatly in different plants, and are materially affected by the general design of the plant, methods of operation, and the nature of the material worked.

To provide for the severe starting and running conditions, there is a tendency to select motors larger than necessary. The result of the low load factor caused thereby is low power factor and low efficiency of the individual motors.

The advantages obtained by the application of motors in brick plants are briefly as follows:

1. Economical Arrangement of Plant. The various departments of the plant can be arranged to the best advantage by the application of individual motors or motors driving small groups of machinery, which is in contrast with the complicated arrangement required by a single driving unit.

2. More Efficient Operation. This is accomplished by the reduction of losses in line shafts and belts and by the restriction in operation to those machines actually required by the work.

3. Protection against Dangerous Overloads of driven machinery afforded by simple control.

4. Increased Output. This is accomplished by the greater continuity of service, and the constant speeds of machinery afforded by individual drive.

One of the points of importance in the consideration of the change over from steam to electric drive is the method of drying the brick. In those plants where heat exhausted from the kilns is used for drying the brick, or where drying tunnels are heated directly by coal or gas, no change is necessary. However, when exhaust steam is used, it will probably be of advantage to consider some other method of drying, in order to eliminate the use of boilers for this purpose only.

While in some cases water or oil is used for lubrication of the die of the brick machine, in some plants the use of steam for this purpose has proven of advantage and in such cases, can be secured by a small boiler located adjacent to the brick machine.

The decision must be made as to whether group or individual drive of machinery would be the better. For plants with storage facilities between the various departments, and the machinery scattered, individual drive will usually be of better advantage, while for plants with all machinery inter-dependent and grouped, group drive would be better.

A-c. motors are almost without exception used by clay 
working plants, because of the extensive use of central station power. This type of motor possesses the advantages of greater simplicity and less parts to be damaged by dust and dampness as compared with the d-c. motors.

The progress of material through a brick manufacturing plant involves the following applications.

Hoist or conveyer from quarry to plant.

In large plants, with a long haul, the clay is transported by an industrial railroad. An economical method is by means of a motor-operated transfer car or locomotive, which mav be operated by alternating or direct current from overhead trolley. The loose material and large amount of dirt around a plant of this kind, makes the third rail system undesirable.

The material may be dumped into storage bins or conveyed direct to crushing or disintegrating machinery after reaching the plant. In case the raw material is shale or rock, crushers and dry pans are usually used, while for soft and stiff mud, refining rolls or various forms of pulverizers are used.

Where the material is located a short distance from the plant, a convenient arrangement is to control the hoist or conveyer and the crushing machinery from the same point.

The usual drive for the conveyor from the storage is by belting from the motor driving the crushing machinery, although in some cases it is more convenient to use an individual motor.

Crushing machinery is usually of such type that belting is the most suitable method of applying motors, although some types of crushers operate at suitable speeds for direct coupling of the motors. Motors with good starting and pull-out torque characteristics are required by all types of crushing machinery.

Dry pans are usually driven by constant speed motors geared to the dry pan shaft. The vibration of this machine is very severe and it is advisable that the motor shaft be rigidly supported by an outboard bearing. It makes an improved arrangement to provide a flexible coupling between the gearing and the motor as this prevents the transmission of vibration to the motor to a large extent. This is especially important with respect to d-c. motors.

An arrangement for dry pan drive has recently been proposed whereby the motor is mounted on the top of the pan, and the motor shaft is rigidly supported by a pedestal bearing mounted upon the frame. Such an arrangement is very compact and should mean a reasonable life to the motor.

The pug mill and auger machines may be driven by motors belted or geared to the respective machines. Because of the large pitch of gears of these machines, considerable vibration results, and flexible couplings should be used if the motors are geared. The auger machine will require more power than any other machine in the plant and may require one-third of the total. In making this application, careful consideration should be given regarding the starting current taken by the motor and the 
capacity of the power plant. If there is no clutch between the motor and the auger, the motor will be required to start frequently, and if the current taken by this motor is near the capacity of the power plant, serious trouble from plant operation may result, due to excessive drop on the line voltage. In smaller capacity machines, the pug mill and auger are often combined in one unit, in which case, belting is the usual method of drive.

The cutters, represses and conveyers between the various machines require little power and may be driven from the motors driving the machines upon whose operation they are dependent, or individually by small motors.

When individual drive is used, the motors are as a rule, geared to the driven machinery, offering the advantage of less space required and lower maintenance costs. For machines which are started without load and are driven by motors 50 h.p. or smaller in capacity, squirrel cage motors will give satisfactory operation.

The operation of the pug mill and auger machine is practically constant, but an occasional stop is necessary. Under these conditions, the machines will be full of material which hardens if the shut down is of appreciable length, and if the machines are not provided with clutches, the starting requirements on the motor are severe. For such installations, a wound rotor motor is advisable.

Motors for blowers and exhaust fans will be required according to the type of kilns and method of drying used. These machines are required to operate 24 hours per day and for these applications, central station power can be used to good advantage, as it eliminates the necessity of the operation of an auxiliary engine at light load at night, as required by engine drive.

The power requirements for making brick vary considerably with the kind of material used, the product made, and the methods used for obtaining the product and to approximate the power required per unit output, is only possible after the layout of the plant is made.

The table on the following page gives an outline of theoutputand power requirements of a number of brick manufacturing plants.

It is to be noted that the soft mud plant making common brick requires the lowest amount of power for production. This is due to the fact that little crushing of material is required. The stiff mud plant requires considerably more power than the soft mud plant, due to increased power for crushing and the power requirements of this type of plant vary greatly, according to the hardness of material.

Considering the power requirements of the individual machines, tests have shown that $35-40$ h.p. is sufficient to drive a 9 -ft. dry pan, when working at full capacity. The dry pan is the most usual grinding machine used in stiff mud plants. The power requirements of auger machines vary considerably, according 


\begin{tabular}{|c|c|c|c|c|c|c|c|c|c|c|}
\hline 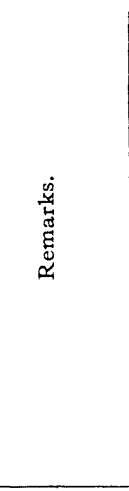 & 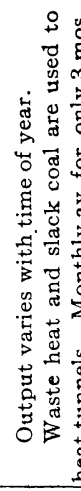 & 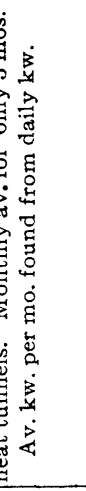 & 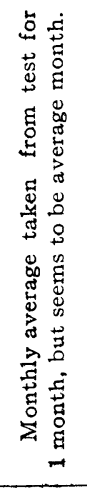 & & 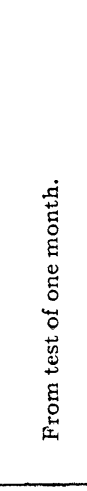 & 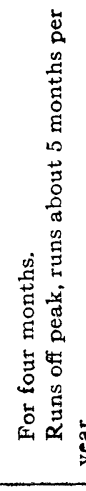 & & 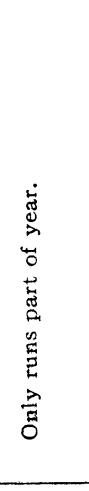 & 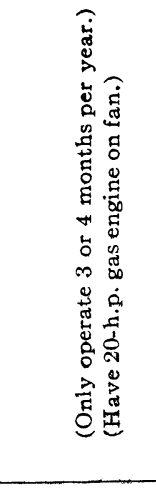 & 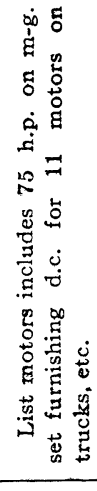 \\
\hline 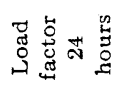 & $\stackrel{\infty}{=}$ & $\stackrel{\infty}{\leftrightarrow}$ & 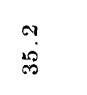 & 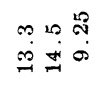 & $\ddot{\infty}$ & $\stackrel{m}{\dddot{y}}$ & $\because$ & $10 \stackrel{0}{0}$ & $\stackrel{0}{0} \underset{\infty}{\infty} 0 \stackrel{1}{\infty}$ & \\
\hline 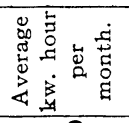 & 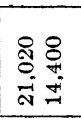 & $\begin{array}{l}8 \\
0 \\
-1 \\
\end{array}$ & $\begin{array}{l}5 \\
\stackrel{0}{0} \\
\infty \\
0 \\
\end{array}$ & 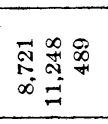 & 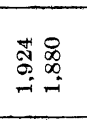 & 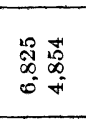 & $\begin{array}{l}10 \\
10 \\
0 \\
0\end{array}$ & 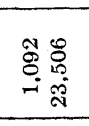 & 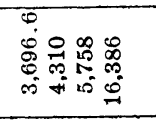 & \} $\\
{\hline \text { 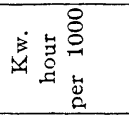 }} &{\stackrel{\leftrightarrow}{\circ}} &{\dddot{N}} &{\stackrel{+}{+}} &{\text { œ } \stackrel{\infty}{\stackrel{\infty}{\sim} \stackrel{\infty}{\sim}}} &{\ddot{\infty}: \dot{\varphi}} &{\text { is }} &{\stackrel{\infty}{\dot{H}}} &{\stackrel{n}{-1}} &{\text { 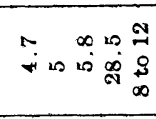 }} &{\overrightarrow{0}} \\
{\hline \text { 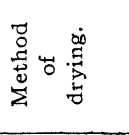 }} &{\text { 党量 }} &{\text { 苞苟 }} &{\text { 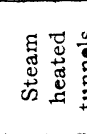 }} &{\text { 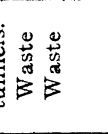 }} &{ } &{ } &{ } &{\text { 妛香 }} &{\text { 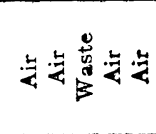 }} &{\text { 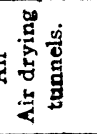 }} \\
{\hline \text { 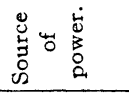 }} &{\begin{array}{l}\dot{s} \dot{0} \\
\dot{v} \dot{0}\end{array}} &{\dot{\varphi}} &{\dot{m}} &{\begin{array}{l}\dot{s} \dot{s} \dot{0} \\
\dot{v} \dot{v}\end{array}} &{\begin{array}{l}\dot{v} \dot{s} \\
\dot{v} \dot{v}\end{array}} &{\begin{array}{l}\dot{s} \dot{0} \\
\dot{0} \dot{0}\end{array}} &{\dot{s}} &{\begin{array}{l}\dot{\theta} \dot{n} \\
\dot{v} \dot{v}\end{array}} &{\begin{array}{l}\dot{\theta} \dot{\theta} \dot{\Delta} \dot{\theta} \\
\dot{ن} \dot{ن} \dot{ن} \dot{ن}\end{array}} &{\begin{array}{l}\dot{2} \text { i } \\
j 0\end{array}} \\
{\hline \text { 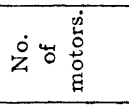 }} &{\infty \infty} &{10} &{\rightarrow} &{N \infty=} &{-10} &{n-1} &{\text { 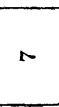 }} &{- \pm} &{\text { NONO }} &{-\stackrel{\infty}{\sim}} \\
{\hline \text { 焉 }} &{\stackrel{\text { N. }}{\infty}} &{\stackrel{1}{=}} &{\stackrel{一}{\circledR}} &{\text { 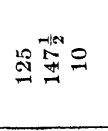 }} &{\text { 品 }} &{\text { 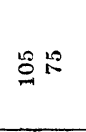 }} &{\stackrel{\leftrightarrow}{0}} &{\text { 윰ํำ }} &{\text { 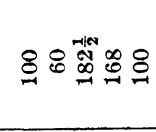 }} &{\left[\begin{array}{c}\infty \\
\infty \\
\infty\end{array}\right.} \\
{\hline \vec{Z}} &{\text { 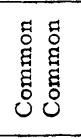 }} &{\text { 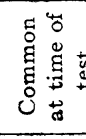 }} &{\text { 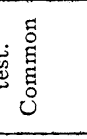 }} &{\text { 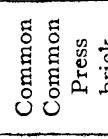 }} &{\text { 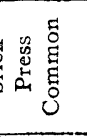 }} &{\text { 㤩 }} &{\text { 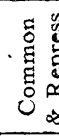 }} &{\text { 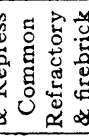 }} &{\text { 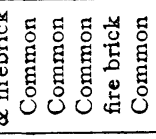 }} &{\begin{array}{l}0 \\
0 \\
0 \\
0 \\
0 \\
0 \\
0\end{array}} \\
{\hline \text { 葶苔要 }} &{\text { : }} &{\begin{array}{l}8 \\
8 \\
8\end{array}} &{\begin{array}{l}8 \\
\stackrel{0}{0} \\
\dot{p}\end{array}} &{\text { 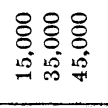 }} &{\text { 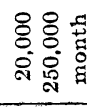 }} &{\text { 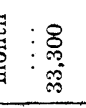 }} &{\begin{array}{l}8 \\
\vdots \\
\dot{+}\end{array}} &{\begin{array}{l}8 \\
\dot{0} \\
\dot{\circ}\end{array}} &{\text { 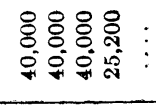 }} &{\begin{array}{l}8 \\
0 \\
0 \\
0 \\
0\end{array}} \\
{\hline \text { 总总苔焉 }} &{\begin{array}{l}8: 0 \\
0: 0 \\
8: 0\end{array}} &{\text { \&. }} &{\begin{array}{c}8 \\
8 \\
\text { is } \\
\text { 15 }\end{array}} &{\vdots} &{\vdots} &{\vdots} &{\vdots} &{\vdots} &{\text { : : : }: \frac{8}{8} 8} &{\begin{array}{l}8 \\
8 \\
0 \\
0 \\
0 \\
0\end{array}} \\
{\hline \text { 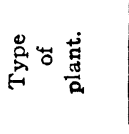 }} &{\text { 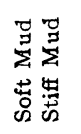 }} &{\text { 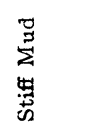 }} &{\text { 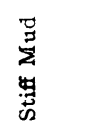 }} &{\text { 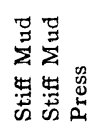 }} &{\text { 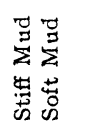 }} &{\text { 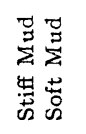 }} &{\vdots \vdots} &{\text { 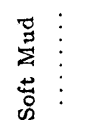 }} &{\text { 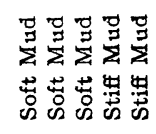 }} &{\text { 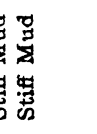 }} \\
$\hline
\end{tabular}


to their size. For machines of capacities up to 7500 bricks per hour, 10 h.p. per 1000 bricks per hour is approximately required, while for the larger machines of capacities, 25,000 to 40,000 bricks per hour, 5 h.p. per 1000 bricks per hour would seem ample. The pug mills will require approximately one-half of the power required by brick machines of the same capacity. The conveyors about the brick plant are a simple mechanical proposition, as to power requirements, although 50 per cent should be added to the calculated power requirements in order to take care of the friction losses. The h.p. requirements of fans and blowers must be obtained from the manufacturers of these machines.

\section{Electricity in the Rubber Industry}

E. W. Pilgrim: Rubber as it is received by the manufacturer of rubber goods is in two forms, crude rubber and plantation rubber.

Crude rubber is gathered from wild rubber trees by natives and is worked up by them into balls about the same shape and half again as large as the American football, and before it can be used it must be washed to free it from dirt, after which it is worked up into sheets and dried.

Plantation rubber is gathered from cultivated trees, washed and dried at the plantation and shipped in the form of sheets.

The first treatment which crude rubber must undergo is washing. The large pieces of rubber are put in a tank of hot water and left to soak until softened. This makes it easy to free the rubber of dirt during the process that follows.

The large pieces, after having softened, are first put through a " cracker." This machine consists of two sets of rolls, both corrugated, and is really a rough washer. In this machine the rubber is torn up and rolled out into rough corrugated sheets. After passing through the cracker several times it is taken over to the finishing washer. This machine is the same as the cracker except that the rolls have finer corrugations. Here the rubber is rolled out into a fairly smooth sheet. Water is kept flowing over the material in both the above mills.

After washing the sheets are dried in a room heated by steam pipes or by hot air blown through by fans. A later process consists of putting the sheets in an oven heated by steam and from which the air is pumped, making a vacuum. Rubber is dried by this process very quickly.

The power required for driving the various machines in the rubber industry varies greatly as, for instance, a washer having two rolls, 16 in. diameter by 30 in. in length used in breaking down scrap rubber averages about 25 h.p., but if used for breaking down pure rubber gum the power required will be about 50 h.p.

The above figures are for individual motor drive. Most mills connect a line of washers to one motor, the motor being connected 
to a line shaft running beneath the floor. The washers being geared to this shaft, the peak load of one machine, which is often 100 per cent more than the normal load, will come during the light load of another machine and normal load is thus maintained on the larger motor. With this arrangement a 100-h.p. motor would be ample for five mills washing scrap rubber and a 150h.p. motor for four mills washing pure gum rubber.

In a washing room having a rough washer containing three rolls, each roll 15 in. diameter by 24 in. long, running at 21 rev. per min.; two finishing washers containing two rolls, each roll 18 in. in diameter by 36 in. long, running at 25 rev. per min., and one tub heater, a 100-h.p. motor is installed and the following data are taken from a test record, breaking down crude rubber.

During this test the rough rolls were working, and the smooth rolls running light, the smooth having been loosened slightly.

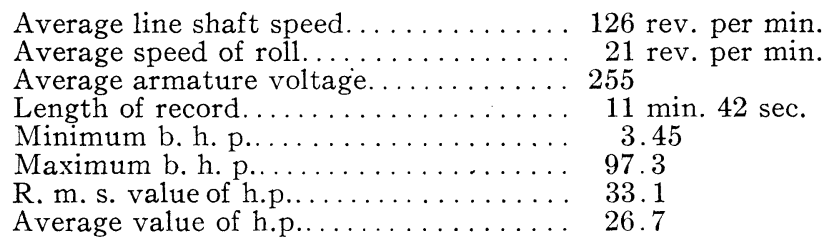

The above consists of both working cycles and periods of running light, while attendant was obtaining raw material.

The following are the values for any working cycle:

Highest average h.p. for any working period...... 53.5

Highest r. m. s. value of h.p. for any working period 54.5

Highest maximum horse power for any working period 97.3

These last figures represent the extent to which the rolls might be loaded provided the operator was kept continuously supplied with raw material, and should be used in case an individual motor is desired to operate each set of rolls.

The following figures cover similar conditions, rough rolls running light and finishing rolls under load.

Average speed of line shaft......... 126 rev. per min.

Average speed of rolls............ $25 \mathrm{rev}$. per min.

Duration of record................ 22 min. $10 \mathrm{sec}$.

Maximum b. h. p............. 49.1

Minimum b. h. p............. 5.5

R. m. s. value of b.h. p.......... 23.4

Average value of b. h. p.......... 20.8

Highest average b. h. p. any working period.................. 41.5

Maximum h.p. for any working period... 49.1

From the above we can assume that if both sets of washing rolls are to be operated continuously under load and driven by one motor, the motor should have a continuous capacity of 96 h.p. and be capable of a momentary overload of 143.4 h.p. 
The peak loads come at a time when the operator throws large pieces of pure para rubber into the cracker. The momentary h.p. is very great but this drops off immediately after the stock is broken down.

Mill Line: The most general arrangement of mixing and warming mills is to connect a large motor to one end of a long shaft running underneath the floor and gearing the mills to this shaft. If there are only two or three mills connected a bar wound induction motor is satisfactory provided the power companies do not object to the starting load in which case motor with resistance in the rotor should be selected. Where there are a large number of mills connected a wound-rotor motor with external resistance must be used.

The mill line is always protected by a mechanical or electrical brake which can be applied in case of accident, from any machine.

In the mixing mills the rubber after it has been washed and dried is mixed with compounds which are thoroughly worked in. After this operation the rubber is stored until needed and before being used is put through the warmer where it is heated and softened to a condition so that it can be used.

The following data are taken from the test of a 375-h.p. motor driving a mill line to which were geared the following machines:

2 mixing and warming mills having one roll 20 in. diameter and the other 22 in. in diameter, each 72 in. long. Speed of rolls $25 \frac{1}{2}$ rev. per min.

1 mixing and warming mill, having one roll 20 in. diameter and the other 18 in. in diameter, each 60 in. long. Speed of rolls $26 \frac{1}{2}$ rev. per min.

1 mill having two rolls, each roll 20 in. diameter by 48 in. long. Speed of rolls 22 rev. per min.

1 mill having two rolls, each 18 in. diameter by 36 in. long. Speed of rolls 34 rev. per min.

1 mill used as a masticator having two rolls each 18 in. diameter by 48 in. long, running at 24 rev. per min.

On a typical run mixing compounds having about 30 per cent para the following results were recorded:

Maximum h.p........................ 345

Average h.p.......................... 220

R.m. s. h.p........................ 225

Calenders: The calender is used for three different purposes: skim coating, which consists of spreading rubber over the surface of cloth; frictioning, which consists of rubbing the rubber into the fabric so that the cloth is entirely filled with rubber compound; calendering or sheeting rubber, which consists in passing the stock through the rolls and taking it off in sheets of different widths and thicknesses depending upon what it is to be used for. In the process of skim coating the top roll is hot and runs at about twothirds the speed of the middle and bottom rolls. The middle 
and bottom rolls are cool. Cloth is passed between the bottom and middle rolls.

In frictioning all three rolls are hot. The top and bottom rolls run at about three eighths the speed of the middle roll, the fabric to be frictioned running between the middle and bottom roll.

In calendering all three rolls run at the same speed. The top roll is warm, middle roll hot and bottom roll cool, and the rubber is taken off the bottom of the bottom roll.

Each of the above operations is performed most efficiently at different speeds and in order to obtain uniform quality of product it is necessary that the speed at which the rolls run during the various processes remain constant as variations in speed with variations in load gives an imperfect product. Because the d-c. motor can be designed for a wide range of speed and controlled so as to give a small increase in speed with each step of the controller as well as the advantage of dynamic braking in case of emergency, this motor is preferred for calender-drives, the usual speed range being from 300 to $900 \mathrm{rev}$. per min. or 235 to $950 \mathrm{rev}$. per min. We know of one or two installations where a-c. motors are used for driving calenders, but on account of the impossibility of obtaining a wide range of speed, the a-c. motor is practically limited to driving calenders where only one class of work is handled.

The power required in calendering varies approximately directly proportional to the speed, although this rule does not apply for the lower speed as the power required is slightly more than a straight line curve would show. Frictioning requires more power as it is performed at a higher speed. Skim coating is done at intermediate speeds and calendering at the lower speeds.

The ideal drive for calenders on which all classes of work are performed consists of a d-c. three to one or four to one adjustable speed motor controlled by an automatic contactor control, the operator manipulating the control from the push button station located on the calender housing. The field rheostat mounted on the side of the calender housing and graduated in yards per minute controls the speed. From the push button station it is possible to start, stop, reverse, or slow down the motor for threading in another roll of fabric.

The following sizes of motors are usually supplied for driving three-roll calenders used in automobile tire factories:

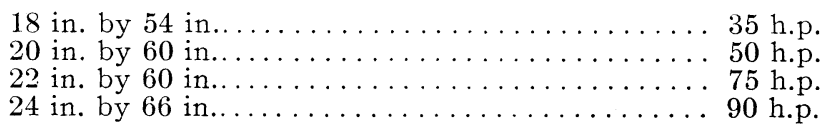

The horse power mentioned above is the power required when the calender is operated at maximum speed.

One of the largest three-roll calenders built has rolls 32 in. in diameter by 90 in. face and requires a 250 -h.p. motor.

The following data were obtained on a calender when running 
rubber compound at a constant thickness of 20 mils and varying speed, width of sheet 36 in.

$\begin{array}{ccc}\begin{array}{c}\text { Motor } \\ \text { rev. per min. }\end{array} & \text { H.P. } & \begin{array}{c}\text { Surface speed } \\ \text { of roll, yd. }\end{array} \\ 462 & 4.88 & 23.5 \\ 500 & 6.25 & 25.5 \\ 535 & 6.22 & 27.3 \\ 571 & 6.35 & 29.1 \\ 618 & 7.67 & 31.5 \\ 670 & 8.15 & 34.2 \\ 638 & 8.17 & 32.6 \\ 600 & 7.02 & 30.6 \\ 570 & 6.73 & 29.1 \\ 500 & 6.20 & 25.5 \\ 455 & 5.62 & 23.2\end{array}$

The above tests were taken on a 16 in. by 44 in. calender and the table indicates the increase of h.p. with increase of speed.

The following table indicates the results obtained from the same calender and the same compound running at the same speed and varying the thickness of the stock.

$\begin{array}{ccc}\begin{array}{c}\text { Thickness of } \\ \text { stock in mils }\end{array} & \text { F.P. } & \begin{array}{c}\text { Ft. per min. } \\ \text { of rolls }\end{array} \\ 20 & 10.4 & 30.3 \\ 30 & 7.7 & 32.3 \\ 40 & 6.10 & 32.7 \\ 50 & 4.96 & 33.2 \\ 60 & 6.24 & 32.6 \\ 70 & 7.00 & 32.2 \\ 80 & 6.38 & 32.3 \\ 90 & 6.92 & 32.5 \\ 100 & 6.46 & 32.6\end{array}$

The above table leads us to believe that the power required at a given speed varies inversely as the thickness. The most important factor which has a considerable effect on the power consumption and one which causes varying results when different conditions are varied is the size of the rolls which are fed into the calender. It is evident that when a large roll of compound is being fed into the calender a large surface of the calender roll is rubbing on the compound and the power required to reduce large rolls of compound to sheets is consequently greater than that required for the smaller rolls.

The following is a list of typical installations:

\begin{tabular}{|c|c|c|c|c|}
\hline $\begin{array}{l}\text { Size of mill } \\
22 \text { by } 60 \text { in. warming . . }\end{array}$ & $\underset{75}{\text { H.P. }}$ & $\begin{array}{l}\text { rev. per } \\
\text { min. } \\
720\end{array}$ & automol & $\begin{array}{l}\text { terial } \\
\text { ile tires }\end{array}$ \\
\hline $\begin{array}{l}10 \text { by } 22 \text { by } 36 \text { in. } \\
\text { rubber refiner. } \ldots \ldots \\
18 \text { by } 36 \text { in three-roll }\end{array}$ & 40 & 720 & “ & “" \\
\hline 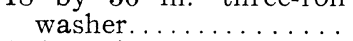 & 75 & 900 & “ & “ \\
\hline 16 by 24 in. sheeter. . . . & 20 & 720 & “" & “ \\
\hline $\begin{array}{l}18 \text { by } 40 \text { in. warming. } \\
24 \text { by } 66 \text { in. three-roll }\end{array}$ & 40 & 720 & “ & ، \\
\hline calender............ & 90 & $300 / 900$ & “" & “ \\
\hline Tube machine... & 15 & 900 & “ & inner $t$ \\
\hline
\end{tabular}


One tube wrapper, one buffing machine and one rag wrapper for automobile inner tubes, 5 h.p. -1800 rev. per min. belted to line shaft.

One 100 h.p. 600 rev. per min. motor driving one 16 in. by 24 in. washer, one $14 \mathrm{in.} \mathrm{by} 30 \mathrm{in}$. tin roll, one $14 \mathrm{in.} \mathrm{by} 34 \mathrm{in}$. tin roll, one 14 in. by 18 in. by 28 in. dust grinder, one wash tub, material manufactured hard rubber novelties.

One 200 h.p. 600 rev. per min. motor driving three 18 in. by 50 in. and one 50 in. by 36 in. warming and mixing mills, material manufactured hard rubber novelties.

One 75 h.p. 720 rev. per min. motor for driving one 16 in. by 42 in. mixing mill, one 15 in. by 24 in. washer, one tube machine. Material manufactured, automobile inner tubes.

The usual arrangement of the factory for the manufacture of automobile tires is as follows:

At the rear of the building are the washers, drying room, and compounding rooms. Along each side and near the windows are the calenders. Between the two rows of calenders are the mixing and warming mills. Cloth drying machines are installed convenient to the calender. Next along one side of the building are the fabric cutters and then the tire wrapping machines. On the opposite side are the vulcanizers. The offices and storeroom are near the front of the building.

L. L. Tatum: There is one point that has been standing out before me very strongly for the last year or so, and that is as to the increased responsibility for the completeness of the equipment on the part of those in the electric art who are making industrial motor applications. The papers this afternoon have brought out a thorough study of the power applications, the type of motor required, and the conditions under which the motor is operated. Machinery people treat that as a foreign art. Due regard to economy requires that most of our applications should be made on new machines, and that means the manufacture of new machinery rather than the rebuilding of existing machinery.

To too great an extent we have considered our responsibility as ended when we recommended suitable equipment. We have not carried our responsibility further to the proper assembly of the equipment on the machine. Many of these machines go into small plants that maintain no suitable electrical force and are at the mercy of the local contractor for assembly and installation, and my own experience has been that the machines suffer a good deal from these local contractors. That fact was driven home particularly one Sunday afternoon this past winter when I was called out to help a poor fellow get his machine running by Monday morning. He could not find any one else. The local contractor had fallen down completely. It was a simple job, but before the owner of that plant gets through with it, there will be trouble. The plant will be condemned by the wiring inspector, and condemned by the safety man. They had on the machine so-called safety features which no safety board would pass. 
The responsibility of the man who provides the motor, in my opinion, should include the complete installation, to see that it is properly mounted, adjusted, and connected, so as to relieve the man who buys the installation from the constant annoyance of condemnation by inspectors of his apparatus, and the expense of rebuilding it before he gets it right.

There are one or two machinery manufacturers who carry their assembly to the complete mounting of the motor and controller, wiring them complete, ready for the attachment of the power wires, which any ordinary contractor can do in proper form. This practise should be the rule, not the exception.

I find that a great many possible users of electrical machinery are afraid to put it in, just because of the trouble they always get into through improper assembly and installation. The responsibility should rest on the machinery man of making the equipment complete. This is a matter of education of the machinery manufacturer which we are in the best position to carry out.

J. C. Lincoln: There was one installation made in a printing plant in Cleveland which may be of interest, in showing how some problems are met. The manager of this particular plant was an "efficiency man". He wanted to find out how the workmen were doing. He knew that some of his job pressmen would start out, and when he was in the room would run the presses so as to get 2,000 or 2,100 impressions an hour, and when he was not in the room they would not get out so many. This installation was put in, and information was given the manager of the plant of the operations of the men in this way: He had some twelve or fourteen small job presses and about eight or ten large presses, varying in size, the presses requiring a motor of from 5 h.p. to 15 h.p. On a large board in his office was placed a voltmeter, and then a meter and lamp for each press in the establishment. Connections were made so that whenever the press was running the lamp belonging to that particular press was lighted. Furthermore, these voltmeters were so calibrated that the impressions per hour were given by the meter. In this way the manager sitting at his desk could look at the switchboard and see at a glance which presses were in operation and how many impressions an hour they were producing. The plan has been in operation for two or three years. We have not heard any complaint about it, and presume it is giving good service.

J. H. Davis: I was very much interested in Mr. Stafford's paper on electricity in grain elevators because the matter of the exportation of grain is of unusual importance on account of the European war. We have two very large elevators which we are about to electrify, and the question of just how to do it is under consideration and has been for some time.

I have not had an opportunity of reading Mr. Stafford's paper very critically, but in looking over it superficially I see no reference to the vacuum system of handling grain. From my viewpoint, it would appear that that system of handling grain offers many advantages over the old method. 
I think perhaps it may not be out of place to mention here some of the difficulties in the way of the present method of handling grain. I presume Mr. Stafford has studied the subject very closely, perhaps much more closely than I have, but it falls to my lot to decide how we shall do these things, so far as our own elevators are concerned. When the cars come to us loaded, we will say with wheat, they have an additional door known as a grain door, made of rough timber and nailed to the car, inside of the regular door, which is closed, and the car is sealed. The cars reach us and we take them in eight- or ten-car lengths into our grain elevator and there we have track pits and the regular door is opened and the grain door is taken down. It is quite a problem, to remove these grain doors. Unless you have actually seen the difficulties involved, you do not appreciate how it delays or slows down the whole operation. What I am getting at is this-by the vacuum system of handling grain we can allow the grain door to stay as it is by simply carrying into the car a reinforced hose, built around a wire frame so as to prevent collapse of the hose, as the air is removed. This method would readily provide for the removal of, the grain, would not necessitate the removal of the grain doors and it would entirely remove all necessity for shoveling the grain through the doors of the cars. It may be that such a method of handling grain will not prove to be practicable. A test has recently been made at Quebec of this method of handling grain, but unfortunately I was unable to have a representative there, but I understand that, while they were in a measure successful, the details of the equipment were not worked out so as to be entirely successful in every respect.

\section{Dredges and Excavating Machinery}

H. W. Rogers: Mr. Rushmore presents a table of manufacturers by industries in which are mentioned, "Iron and Steel" and "Copper, Smelting and Refining". Both of these industries naturally suggest the mining industry on which they are dependent and with which they are closely allied. Under the heading of "Costs", Item 4 , reference is made to the economic value of electric drive, which introduces the subject of the electrification of dredges and excavating machinery.

In so far as the mining industry is concerned this type of machinery may be classed under the following heads:

1. Dragline excavators.

2. Revolving shovels.

3. Railway shovels.

4. Strippers.

5. Hydraulic dredges.

6. Elevator dredges.

The dragline excavator or bucket-scraper has a limited field of operation in the California gold fields but otherwise is confined almost entirely to contracting work, while the revolving shovel, railway shovel, and stripper are used very extensively in mining 
operations, particularly in the iron and copper mines of Michigan and Minnesota, the copper mines of $U$ tah and the coal fields of Kansas, Missouri and Virginia.

The dragline excavator might be classed with the locomotive crane and revolving derrick as it is of similar construction, and, since such machines operate on a very much slower cycle than the shovel, which is equipped with a rigid dipper handle, they may readily be equipped with either d-c. or a-c. motors depending on the source of power available. In the electrification of a shovel there are many important points to be considered and what may be said of the railway shovel is equally true of the revolving shovel and stripper, the latter being really a revolving shovel of a much larger type and greater capacity.

There is probably no other class of machinery that presents a duty cycle as severe as that of the shovel, which is very short, varying from 7 to $12 \mathrm{sec}$. on the hoist, from 7 to $12 \mathrm{sec}$. on the thrust, and from 10 to $18 \mathrm{sec}$. on the swing, making a complete cycle in from 17 to $30 \mathrm{sec}$. and the motor to meet these requirements must have a sufficiently low armature inertia to permit of rapid acceleration and quick reversals under small power. It should also be a motor of rugged design as it must be subjected to severe overloads and shocks and frequent reversals. This is especially true of the hoist motors, and, to a lesser degree, of the swing motor; the thrust motor being practically stalled during the digging operation, although it may revolve or overhaul, according to conditions, and is operated at full speed only after the hoisting operation is completed.

In laying out an electric shovel drive there are really four things to be considered; namely, the speed at maximum torque, the speed at light load, the power required by the motor, and the gear ratio. An increase in the gear ratio results in a decrease in power at both light and heavy loads, and increase in the speed at heavy loads, and a decrease in the speed at light loads.

The d-c. series motor has the characteristics of the steam engine, in that it gives its heaviest torque on starting, speeds up under light loads, and slows down under heavy loads. It is much easier to control and requires considerably less apparatus, in so far as the control is concerned, than the a-c. equipment.

With the a-c. slip-ring motor it is impossible to obtain the maximum torque on starting; and the light-load speed, which is very important, is limited by the synchronous speed. The only means of improving this disadvantage is to reduce the gear ratio or use a higher speed motor, either of which methods would mean an increase in the capacity of the motors and an increase in the inertia, which would result in an increase in the power required and a slower acceleration, both of which are undesirable. Under such conditions the natural result is a much larger $\mathrm{kv}$-a. capacity in transformers for the induction motors than the $\mathrm{kw}$. capacity of motor generator set for the d-c. motors.

There is undoubtedly a greater demand for electric shovels for a-c. operation than for d-c. operation, but neither type of 
motor should be applied without a full knowledge of the existing conditions and the characteristics of the steam engine, as misapplications will only tend to defer progress in this field of engineering. A very careful study of this subject in connection with existing electric shovels and thorough testing has proven beyond all doubt that the d-c. series motor is better adapted to this service than the a-c. slip-ring motor, and, although it is possible to operate a shovel with slip-ring motors the disadvantage of such an application render it undesirable.

It can be safely said, however, that with a proper application of motors; the electric shovel will equal or surpass the steam shovel in every respect and will eventually replace it. Although the electric shovel requires an increased investment, the reduction in labor and repair charges and the elimination of boiler and feed water troubles will warrant it.

The saving in operating expense of the electric shovel over the steam shovel will depend somewhat upon the comparative cost of coal and electric power and will vary for different localities, but it should be remembered that the electrically operated shovel eliminates the fireman, the watchman, the coal passer, teaming of one-half day, the use of water, and considerable waste. The natural increased wear and tear of parts having a transverse motion as compared with those having rotary motion should be considered.

The following data applies to one of the larger types of shovel, but is typical of all shovels and clearly indicates what may be reasonably expected of the electric shovel. In these figures no account whatever has been taken of the possible saving in the cost of fuel as this must be considered for each individual case.

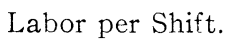

Shovel runner......................

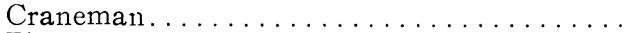

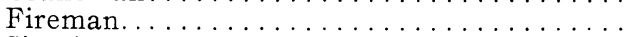

Six pitmen at $\$ 1.75 \ldots \ldots \ldots \ldots \ldots \ldots$

One watchman.

One coal passer..................

Teaming ( $\frac{1}{2}$ day $) \ldots \ldots \ldots \ldots \ldots \ldots \ldots$

Oil and waste.

Total.

$\$ 30.25$

\section{Steam Electric}

$6.00 \$ 6.00$

$4.00 \quad 4.00$

2.50

$10.50 \quad 10.50$

1.75

1.50

2.50

1.50

.75

Saving, electric over steam..........21.25

$\$ 21.25$

$\$ 9.00$ per shift.

For convenience in comparing the costs of operation on steam and electric shovels the costs are all reduced to a day basis.

Electric

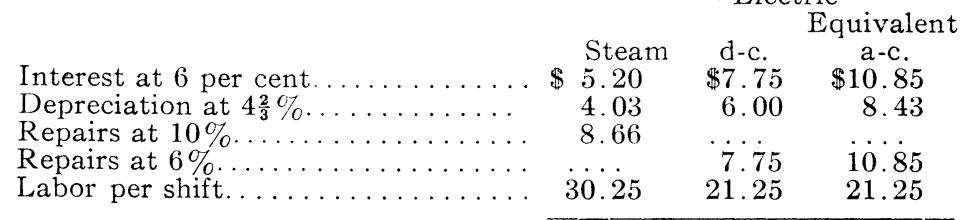

Total cost per shift. 
It has been assumed that, owing to weather conditions, delays, etc., the shovel working year consists of 150 days, and the above figures are based on this assumption; also that the shovel is only working one shift a day.

If the shovel works three shifts a day instead of one shift a day, the interest and depreciation will remain the same, provided the shovel is kept in repair. It is reasonable to assume that the repairs will increase when working three shifts, but not in direct proportion; therefore, this item has been increased 50 per cent.

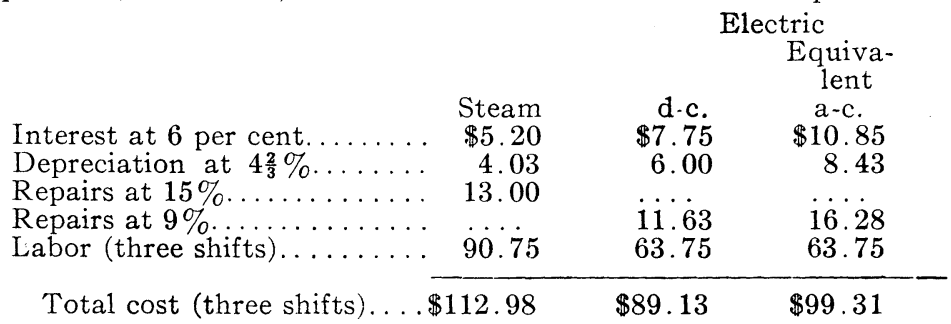

These figures clearly indicate that the electric shovel is a better proposition than the steam shovel, that the d-c. equipment is far superior to the a-c. equipment and that the saving in operating expenses will warrant the increased investment.

The control on either the d-c. or the a-c. equipment is reversible and entirely automatic, all panels being equipped with automatic acceleration, the hoist and crowd panels being also equipped with a "jam " relay which inserts resistance in the circuit in case of very heavy overloads but does not open the circuit, the resistance being automatically cut out again by the same relay when the overload disappears. The master controllers are located similar to the operating levers on a steam shovel so that a steam operator will be entirely at home on an electric shovel.

In selecting a shovel equipment it should be remembered that although it is possible to operate with alternating current, it is cheaper to use the d-c. equipment, even with a motor-generator set, and have an outfit which more nearly approaches the characteristics of the steam shovel, and has much simpler control apparatus and requires considerably less power to operate it than the a-c. equipment with transformers.

The hydraulic or suction dredge has never been favorably considered for mining operations although the modern elevator dredge followed closely and was, in a large part, due to an attempt to mine with the aid of powerful pumps which were suggestive of a more highly satisfactory method. It has long been used, however, as a successful machine, by contractors for excavation of material below the water level and, although not designed for the excavation of rock, such material frequently passes through the pump without any difficulty. Ordinarily it is used in sand, gravel or loam, although there is one at Columbus, Ohio, working in blue clay and one at Calumet working in copper tailings. 
The electrical equipment of such machines is not entirely new as there are quite a number that have been in successful operation for several years.

The greater portion of them, however, are steam operated.

Ordinarily the equipment consists of the main pump motor, the cutter motor, the winch motor, the service pump motors and bilge pumps, with the necessary control and switchboard but these may be and often are supplemented by a compressor motor, a small motor-generator set for the searchlight or an additional motor for operating a "giant." The operation of such machines is practically continuous and it is an ideal application for a-c. induction motors. The main pump, which is by far the greater portion of the load, may vary between 200 h.p. and 1250 h.p., depending on the size of pump and the head against which it operates. Since the greater part of the head is friction head and the discharge line varies in length between wide limits it is necessary to compensate for this change in the speed of the pump and consequently a variable speed induction motor should be used with provision for from 25 to 33 per cent reduction in speed.

Both the cutter and winch motors should be of the variable speed type while the remaining motors may be squirrel cage type. While there may or may not be a saving in the cost of power, there is a saving in labor and repairs and a considerable saving in the first cost of the dredge resulting from the use of motors.

The hull may be smaller and the operating hours longer, while the dirt and grease resulting from the use of boilers, steam engines and coal bunkers is eliminated.

The elevator dredge of the close connected bucket type is used to a certain extent for excavation but is largely confined to gold and platinum mining. It varies in capacity from $3 \frac{1}{2} \mathrm{cu}$. $\mathrm{ft}$. buckets to $16 \mathrm{cu}$. ft. buckets and consists essentially of a digger or bucket line; revolving screen, sluice tables and boxes, stacker for carrying away the tailings, high and low pressure pumps, priming pumps, amalgamator and occasionally a sand pump and "giant." There are more than a hundred of these dredges operating in the country and although some are equipped with steam engines, the greater part are electrically driven with a-c. motors.

The steam driven dredge can hardly be considered economical in sizes larger than $7 \frac{1}{2} \mathrm{cu}$. $\mathrm{ft}$. and it is practically impossible to operate the largest ones with steam as there is no available space for such an equipment, in fact, the larger sizes of dredge practically owe their existence to the electric motor.

\section{The Sugar Industry}

C. A. Kelsey: Few people realize the extent of the sugar industry. Sugar is commonly considered as a luxury but although a large part of the total production of sugar is used in the manufacture of confections there is still a very considerable amount used directly as a food product. 
The total world production of cane and beet sugar for the season of $1913-1914$ was $18,687,000$ tons, of which $9,777,000$ tons was cane sugar. The United States imported in the year 1913, $2,890,667$ tons but produced only 852,472 tons, making a total consumption of $3,743,139$ tons. This gives a per capita consumption of $85.4 \mathrm{lb}$. per annum. Of the above amount consumed in the United States, cane sugar constitutes the greater portion. the amount of beet sugar being a very small portion of the total.

Briefly the process of producing sugar from cane consists of expressing the juice from the cane, evaporating the water, crystallizing the sucrose, and separating the sugar from the molasses.

The cane is delivered to the mill on special flat cars having the sides and ends of open construction. There are two ways of delivering the cane from the cars to the cane hopper. First, by transfer hoist, whereby portions of a carload are lifted out of the top of the car by cables which have been passed around the cane. This requires a hoist motor mounted on a standard hoist. Second, the car is switched on to a track section which can be tilted either sidewise or endwise. In the former case, the platform can be tilted around a balanced point requiring therefore a very small motor of intermittent rating. Where the car is tilted endwise, a hoist motor mounted on a standard will generally be employed. This requires a motor and hoist of sufficient capacity to lift half of the combined weight of the car and cane.

The cane is dumped in to a hopper from whence a conveyer pulls the cane up on to the main cane carrier. The idea of breaking the conveyor up into two sections is to provide means for depositing a uniform layer of cane on to the section feeding the crusher. Both sections of the cane conveyor require variable speed drive. The second section or main carrier requires variable speed in order to give a constant feed to the crusher, depending upon the character of the cane and the desired rate of grinding.

The crusher consists of a set of two corrugated rolls and is intended to break up the cane into short sections and to lay it open so that the main rolls can force out the remaining juice. The main rolls are adjusted to deliver a constant thickness of crushed cane to the succeeding rolls. As the crusher extracts about 65 per cent of the total juice, the portion going to the first mill is composed largely of fiber. With a variation in the percentage of fibre content in the cane coming from different sections or at different periods of the season, the amount of crushed cane delivered by the crusher with a constant feed, will vary. As the rolls require with a given speed a constant rate of crushed cane the crusher must operate at variable speed.

An operator is required at the crusher to regulate the feeding of the first roll and as alternating current is best suited for the general mill conditions, a variable speed motor of the woundrotor type is satisfactory for the service.

As mentioned before, the main rolls are adjusted for a constant spacing between the rolls. A variation in the character of the 
cane producing a higher or lower percentage of fiber or a variation in the rate of grinding, calls for both a difference in the relative and absolute speeds of the different rolls. The relative speeds can be obtained by suitable gearing to motors of the same speed where the mills are to be individually driven. These speed ratios are, however, suitable for one class of cane. With a varying cane it is desirable to readjust the relative speed. Variable speed motors have not proven satisfactory under these conditions as the load is found to vary from time to time even when care is taken to produce a uniform feed. The variable speed a-c. motor under these conditions gives an unsatisfactory speed regulation, rendering it difficult of control.

There are times when on account of shortage of cane or some reduction in the capacity of the sugar house, that it is desirable to keep the rolls running at reduced output. As mentioned before the speed control of a variable speed motor, driving cane rolls is unsatisfactory. A means of meeting this requirement, is however, had, in reducing the frequency and voltage of the a-c. circuit, by means of the reduction in speed of the prime mover. Where the pumps have been designed to meet this condition, the frequency of the whole power system can be reduced, as all of the pumping and conveying apparatus can properly be correspondingly reduced in speed. One exception to this is the centrifugals, which must be operated at their proper speed in order to insure completely drying the sugar crystals. This can be taken care of, however, by splitting up the power circuits leaving the main rolls to be driven by an independent generator. The motors for the main rolls should therefore be constant speed type, but on account of their size, and the high static friction, which they have to overcome, they should be of the wound rotor type with a resistance for starting purposes only.

The crushed cane coming from the last set of rolls is called bagasse, and is conveyed by scraper type of conveyers to the furnaces, usually located between the boilers. In a properly electrified sugar mill the bagasse should meet all of the requirements for fuel with the exception of a very small amount of wood required to kindle the bagasse. These conveyers operate at constant speed and as the material is soft and not liable to jam the conveyer, constant-speed squirrel cage motors are here employed.

The juice extracted by the crushing plant is delivered to a screen where particles of cane are filtered and left on the screen. A scraper conveyer takes the cane refuse from the screen and deposits it on a cross conveyer, which in turn dumps it on to the cane passing between the first and second set of main rolls.

The raw juice is pumped to alkalizing tanks where milk of lime is added. This is to neutralize the acids formed by fermentation and to produce insoluble compounds from the nonsugar element. Centrifugal pumps are here employed, driven by constant-speed squirrel cage motors. 
The milk of lime is produced in the plant by the solution of slaked lime, the action taking place in a small tank provided with a paddle for stirring up and mixing the contents. From here it is pumped to a storage tank. A small centrifugal pump is here used to discharge the mixture. The motor is a constant speed, squirrel cage type.

The tanks into which the raw juice is discharged and in which the milk of lime is added, are provided with some means of mechanically mixing the milk of lime and the raw juice. The paddles are either driven direct by vertical motors or geared down to horizontal motors, in either case constant speed squirrel cage motors are used.

The alkalized juice is then pumped through a heater from whence it discharges into defecator tanks. Here the juice is brought up to the boiling point in open tanks. The heat acting on the albumenoids forms a flocculent precipitate. Part of this settles to the bottom and part rises to the surface, forming a thick, black dirty scum. The clear liquid forms in between two layers and is then decanted and pumped to the evaporators or multiple effects. A centrifugal pump is here used driven by a constant speed squirrel cage motor. The scum and sediment are diluted with additional water and then passed to the filter presses. The nature of the material requires a triplex pump. The pump is driven by a constant speed squirrel cage motor. The size of the motor permits its being thrown on to the line in case a compensator does not give high enough starting torque. The filtered juice follows the path of the defecated juice while the filter cake is dropped down from the filter presses to a conveyor which carries the cake to a car whence it is transported to the field and used for fertilizer.

The defecated juice flows through the multiple effects where it is evaporated down to a consistency of syrup. Evaporation takes place under successive stages of vacuum and correspondingly lower temperatures. The syrup is either pumped to storage tanks near the vacuum pans or flows by gravity. Centrifugal pumps are here used driven by constant speed, squirrel cage motors. The condensed vapors from the juice in the multiple effects are drawn off from the different vessels and are either pumped to a tank for use as maceration water at the rolls or discharged to the hot well. Centrifugal pumps are here used driven by constant speed squirrel cage motors. The syrup is drawn up into the vacuum pans where it is boiled to grain. The first sugars, that is those sugars coming from the original boiling of the syrup, are let out of the pans directly into a tank over the sugar centrifugals. Here the sugar and molasses called massecuite is fed into centrifugal machines. The centrifugal machine is practically the only machine in the sugar mill requiring a specially designed motor. This refers to the direct coupled motor. The centrifugal is first loaded with a charge of massecuite. It is brought up to speed, requiring a high accelerating 
torque. It is allowed to run for a minute or two, depending upon the grade of the sugar, and is then brought to rest by a brake. The molasses is thrown out by centrifugal force through the wire gauze lining of the centrifugal and the sugar crystals are left in a thick layer on the inside surface of the centrifugals. After dumping out the sugar by mechanical scoops or by hand, the centrifugal is again loaded and the process repeated. The direct coupled motor must be designed to accelerate the centrifugal quickly and bring it up to a predetermined speed. It is usually operated a short time at top speed so that the ventilation is limited and a fairly large motor must be utilized, in comparison to the accelerating and running torques.

The molasses is mixed with the syrup coming from the multiple effects in an attempt to crystallize more of its sucrose contents. Usually the massecuite produced in this manner is discharged from the pans into crystallizer tanks. These tanks are provided with paddles intended to keep the contents in slow motion. The sugar crystals are thereby brought into contact with the noncrystallized sucrose and grow larger. These crystallizers are driven by constant speed squirrel cage motors.

The sugar discharge from the centrifugals drops into either a screw or vibrator conveyer and discharges into a bucket conveyer leading to a bin from whence the sugar is discharged into bags for shipment. These conveyors are usually driven from the main centrifugal shaft where group-driven centrifugals are employed, or can be driven by individual motors of the constant speed squirrel cage type.

Where the centrifugals are belted they are grouped and shaft sections are driven by constant speed squirrel cage motors.

The circulating water for the condensers is pumped by centrifugal pumps, driven by constant speed motors. These motors may be squirrel cage type or wound-rotor type with starting resistance depending upon their size as compared with the power system.

The molasses from the centrifugals is pumped to the storage tanks serving the vacuum pans or to the outside storage tanks by triplex pumps. Constant speed squirrel cage motors are suitable for this service. The vacuum pumps and air compressors when used can be satisfactorily operated by constant speed induction motors, either of the squirrel cage or wound-rotor type, depending upon the size of the motors in relation to the power system.

The blowers for the boilers are best driven by variable speed motors, to provide a means for varying the furnace draft. Wound rotor motors are suitable for this service.

The boiler feed pumps should be capable of delivering a variable amount of water to the boilers. This can be accomplished by driving them by variable speed motors or the discharge of the pump can be throttled.

There are miscellaneous applications around a sugar-mill 
factory, such as driving service water pumps, laundry tubs for the filter bags, the carpenter and machine shops, but these applications are simple and not peculiar to the sugar industry.

In general, it may be said that the application of motors to cane sugar mill apparatus consists in a detailed study of the particular apparatus to apply standard motors. The pressure heads and quantities of the various liquids to be pumped are determined by the layout of the mill and these data must be collected at the mill and the proper pumps and motors selected. The same applies to the conveyers, blowers and miscellaneous belted and direct-coupled apparatus.

\section{The Paper Mill Industry}

W. L. Merrill: Experience has shown that with the exception of driving the variable speed end of paper machines themselves, the a-c. motor offers a great many more advantages than the d-c. motor and at the present time is being generally used throughout the industry.

For convenience in the following table the motors have been divided into four types designated: A--Squirrel Cage Motors, B-Internal Resistance Motors, C-Collector Ring Type of Motor, D-Synchronous Motors.

A--Squirrel Cage Type of Motors: The squirrel cage type of motor is essentially a constant speed motor and the speed can not be appreciably changed, has high starting torque, high efficiency, and high power factor. In the larger sizes it is customary to use compensators for reducing the voltage applied to the motor at the time of starting. This is not to protect the motor, but to avoid heavy fluctuations on the line. It will, therefore, be seen that squirrel cage motors should not be used; first, where speed reductions are required; second, where at the time of starting it is desired to start slowly or to "jog" the load; third, where sudden shocks are objectionable at the time of starting, such as in the chain drive on beaters. In group drives where belts are used, these shocks are absorbed partially, by the belts and are not objectionable.

B-Internal Resistance Motors: The internal resistance motor has high starting torque, high efficiency, and high power-factor, similar to the squirrel cage and has the advantage of being able to gradually increase the speed of the motor until the machinery comes up to speed and is satisfactory for service where the load has small inertia, or is practically all friction and the time of acceleration does not exceed about one minute. The internal resistance, however, can not be made large enough to give any speed regulation and the motor must be treated as a constant speed machine. This motor is satisfactory for group drives of average service conditions, such as screen rooms, sulphite departments, etc.

C-Collector-Ring Type of Motor: The collector ring type of motor has a high torque, high power factor, and efficiency some- 
what lower than the above two types. It may be either constant speed or varying speed. As a constant speed motor it should be used where heavy starting duty is required, since it is possible to proportion the external resistance used in connection with a drum controller to meet almost any condition of starting required. With liberal resistance grids, several successive starts can be made without injury to the motor or controlling appliances, such as breaking a wood conveyer loose when jammed with ice or for starting heaters after the stock has settled. A squirrel cage motor under similar conditions might injure the conveyor or jump the roll out of its bearings. As a varying speed motor it can be used where a certain amount of speed regulation is required provided it is not objectionable to have the speed change as the load changes; $e . g$., cranes, hoists, etc. It is not applicable to drives where constant speed is desired at different loads with one setting of the controller. As the load decreases, the speed increases and vice versa.

D-Synchronous Motors: Synchronous motors have low starting torque as compared with the above types, high efficiency, and an adjustable power factor and can be often used advantageously for improving the power factor of the system. Before installing a synchronous motor, however, conditions of operation should be thoroughly studied, as many times the lower power factor is due to many motors on the system running at partial loads.

Synchronous motors should not be installed on line shafting or individual machines where a heavy starting torque is necessary, unless they are provided with clutches or some means of relieving the load at the time of starting. The starting torque, in general, is limited to about 30 per cent of full load running torque. The synchronous motor can be used to advantage to supply auxiliary power to a line shaft already driven by a waterwheel or an engine, power being obtained from another station.

The synchronous motor also has a field in the industry in connection with low pressure turbines. Where there are one or two reciprocating engines, it is often advantageous to install a low-pressure turbine and supply power to various motors throughout the mill; also to "pump back" on the engine or main line shafting with the synchronous motor. A combination of the engine or turbine and the synchronous motor is self-regulating.

Drives in General: It is undoubtedly needless to call attention to the desirability of having all transmitting parts, such as belts, rope drives, gears and chains of ample proportion throughout the mill. Large motors which are to run continuously on heavy work with belting under severe conditions should be equipped with three bearings; two-bearing motors under these conditions have in many cases proved successful, yet the occasional renewal of the bearing linings more than warrants the added expense of the three-bearing installation. 


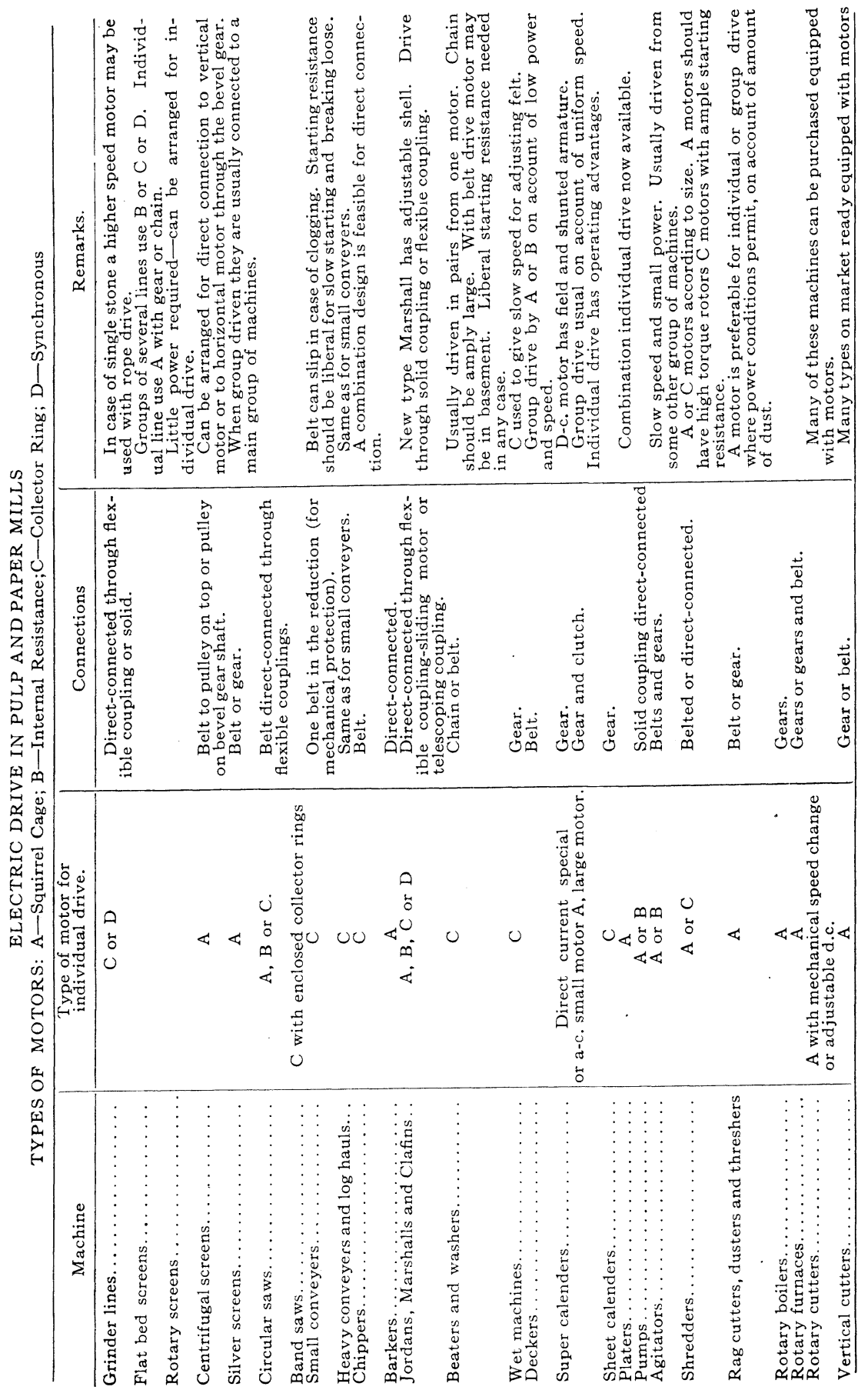


Silent Chains: Silent chain drives, particularly, should be chosen of liberal size for the work they are to do. This is true of beaters, where continued sudden shocks are apt to come on the chain.

\section{The Portland Cement Industry}

C. C. Batchelder: The Portland cement industry affords a good illustration of the application of electrical apparatus on a large scale where a careful selection of the equipment and attention to comparatively inexpensive protective measures have a great bearing on the service obtained. Cement making is primarily a grinding process and involves reducing the material to a fine powder twice in the course of its manufacture, once before and once after burning. This means a large specific power consumption. Each barrel of cement requires about 20 h.p-hr. in the course of its manufacture, and as the average production of American cement plants is over 2000 barrels a day the aggregate power used by the industry is enormous. Cement manufacturers are vitally interested in power production and distribution. It makes up a very appreciable portion of the cost of their product and must therefore be economical. Its supply must be continuous and reliable, and at the same time capable of adjusting itself to a demand that varies with the seasons.

Cement mills have a few characteristics which differentiate them from most other manufacturing plants.

The principal difficulty with which motors and control appliances have to contend in cement plants is the large amount of abrasive dust in the air. While an increasing amount of attention is being given to dust elimination and collection, there are very few plants in which the air in the rooms containing the crushing and grinding machinery is clean enough to allow motors with unprotected bearings or collectors to operate without requiring an abnormal amount of attention. The engineer must meet this condition by putting the electrical apparatus in separate motor rooms whenever practicable, by specifying bearings protected from dust by shaft dust washers and tightly seated oil well covers, and by selecting low-speed motors. Ordinary gearing should be avoided, and if used at all, should be protected by tight cases. It is a good plan to have compressed air piped throughout the plant so that the motors can be blown out at regular intervals. Control appliances should be of as simple a nature as possible, and if relays are used they should be enclosed by dust tight covers, or installed in cabinets if they must be placed in dusty parts of the plant.

Crushing and pulverizing machinery is usually rather roughly built and to prevent excessive vibration and shock being transmitted from the machines to the driving motors, requires that the mechanical details of a motor installation be laid out in a conservative manner. Motor foundations should be rigid; flexible couplings should be used between direct-connected units; and bearing pressures and rubbing speeds should be kept low. 
Much of the cement-making machinery requires somewhat more than normal running torque at the instant of starting, and the motors must be capable of exerting this torque if trouble is to be averted. This does not affect the design of d-c. and slip ring induction motors, but as the greater part of cement machinery is driven by squirrel cage motors it is usually necessary to bear this starting torque requirement in mind when selecting the electrical equipment. As a matter of fact a change in the motor design to secure higher torque is very seldom necessary, and standard machines can take care of the great majority of drives satisfactorily. This has been especially true since the introduction of practically indestructible rotor construction.

High room temperature is a factor that sometimes affects the motor equipment of the kilns, and dryers, and various expedients have been adopted to protect the motors driving this machinery when the conditions were such as to require special precautions, such as placing the motors in ventilated tunnels, or in spearate rooms.

While the general tendency of industrial engineers is toward the adoption of individual drive, there are a few cases in cement plants where a well worked out group drive will give better results. This is particularly true of small elevators and conveyers, which are often subject to rather violent load fluctuations, so that individual motors must be of considerably larger capacity than required by the average load of machine, while if grouped, the driving motor can be safely worked at practically full capacity.

Careful attention to the features in which cement mill service is especially severe will make an electrical installation almost as free from trouble as in more favorable industries, while neglect of the proper precautions in laying out a motor equipment may cause a large expense either in the form of maintenance charges or the cost of changes after the equipment is installed.

\section{The Handling of Freight in Terminals}

R. H. Rogers: As recorded in Mr. Rushmore's paper, "The valuation of electric motor application

is so special as to necessitate its separate statement for each industry."

This sentence paves the way for an exposition of the advantages of electric motors in an industry closely interwoven with every kind of manufacturing, namely: the handling of freight in terminals - the Siamese twin with transportation.

The movements of raw materials, of processed materials, of manufactured and assembled products and food stuffs on their halting way to consumer and the subsequent return of scrapped material, waste and by-products to the grand circuit necessitate a continuous high-pressure system of freight handling at every twist and turn, at the beginning and end of every transition from one classification to another and in every community. 
Until recent years this great labor has been performed by hand and the first part to be mastered by power was the handling of bulk materials. Package freight handling has only recently been invaded by mechanical methods involving machines and motors.

Steam power and hydraulic and pneumatic methods have been introduced and are still maintained to some extent but the really successful agent and the thing that has done most to mechanize this work is electricity through its field piece-the motor. Motoroperated machines for the handling of bulk freight are:

Various forms of derricks operated by multiple drum and often multiple motor winches.

A multitude of machines under the general title of cranes with one, two, three or four motions with corresponding motors.

Gigantic machines and combinations of machines for specialized work in great quantities, as typified by ore and coal bridges, ore and coal dock equipments and car dumpers using motors in great variety of sizes and characteristics with corresponding highly developed control apparatus.

Continuous conveyers for free-flowing bulk material, used for elevating, horizontal and lowering movements between cars, ships, storage piles or warehouses and elevators; equipped with motors section by section with self-protecting control devices.

Complicated engineering problems are involved in the design and selection of motors and control to secure the greatest possible speed in the motions and the greatest tonnage per motion that the fabric is capable of handling. Endurance, cost to install and cost to operate also are important factors in the problems.

In handling package freight not so much progress has been made because of the multiplex sorting and distributing necessary and the great variety of forms in which package freight appears. However, machinery is being rapidly developed that can cope with the varied requirements of freight terminals and because of the novelty of this class of motor application it is little understood or appreciated as a prospective power load.

The principal methods used in this branch of the work are:

Storage battery vehicles, such as-

Commercial trucks.

Industrial or battery trucks.

Battery truck cranes.

Battery tractors with trailers.

All these machines require battery charging equipments and consume (due to the low over-all efficiency) much more power than their output would indicate. From the user's standpoint, however, the current consumed is of very minor importance compared with the advantages gained by being able to move the tool about, independent of any power circuit.

Monorail apparatus composed of trolley cars suspended from a single overhead rail and equipped with winches and various devices for lifting and carrying freight. 
Conveyers, either fixed or sectionalized and portable; operated from fixed circuits or flexible cables run to nearby power services. These machines have simple motor and control problems and are becoming popular wherever quantities of packages are moved moderate distances.

Derricks are used to a great extent in the loading and discharging of ships and lighters; usually steam-driven but lately largely actuated by portable or fixed electric winches on wharves. High speed with reliable braking and moderate load capacity are their usual characteristics and the control features are capable of giving greater convenience, safety and dispatch than the ordinary steam winch with crank throttle, foot brake and reverse mechanism.

Winches are applied in a variety of ways to warehouse work, wharf work and shipping in general, as they take advantage of the universal wire rope and hook that can go anywhere after a package and bring it out.

Cranes used in package freight handling are varied in design and manner of doing their work - not very largely adopted in this country, but being more and more widely considered. A number of motors are required on each crane to accomplish the various motions with proper efficiency and in the best manner. Some cranes combine conveyer principles in their make-up, giving continuous discharge rather than intermittent drafts.

In the improvement of any terminal the features most sought after are:

Dispatch: For rolling and floating stock earn dividends only while in motion. The welfare of communities depend upon rapid transfer of the commodities that flow according to the laws of supply and demand.

Increased capacity: Because freight movements are subject to peaks of severity and frequence, and unless able to cope with them, congestion often occurs of far reaching consequence and economic loss.

Safety, both to persons and property, is much sought after, as damage claims for lost, broken or spoiled freight amount to a huge sum and injuries to employees are of very common occurrence.

Service: It is the aim of all terminal authorities to increase the service rendered to patrons on account of competition and the new desire to cultivate the good will of the public- " the oxygen for the lungs of business."

Economy: When it is understood how great are the costs of freight handling as compared with freight hauling, it becomes of paramount importance to modernize methods to something of the efficiency attained in hauling. Shipping by sea costs onehalf mill per ton-mile, hence a difference in handling, say from 45c. per ton to 12c. per ton (not extraordinary), would equal the cost of hauling from Havana to Boston, or, if by rail at $7 \frac{1}{2}$ mills per ton-mile, from Philadelphia to New York. 
The costs of handling bulk freight have been reduced in a few years from 40 to 7 cents per ton and while a reduction to this extent cannot be expected in package freight, nearly as good results have been attained in specially favorable classes and lessened gains in other more difficult cases.

The electric motor possesses great advantages over any other known means of actuating these varied devices both for bulk and package work and an outline of these advantages will be in order.

(a) It transforms the energy of transmission to energy of useful motion closer to where the motion can be used than any other power device.

(b) By virtue of a variety of designs a wide range of characteristics are available. Some are adapted for certain kinds of work and others for different circumstances. Not so with steam, air or water as each has fixed characteristics.

(c) Nicety of control is inherent with electric devices. Speeds under the various circumstances can be determined and set in advance. Braking can be regulated and applied surely without effort on the operator's part. Acceleration is automatically regulated as are the various other functions of the apparatus. Remote control is easily arranged so that operators can see their work and even go along with it. Motors may be widely scattered to do their work best but the control of all can be brought to the most sightly place for one man's convenience.

(d) Power can be subdivided into comparatively minute portions without sacrificing efficiency, thus accommodating small power requirements so often prevailing in package freight work.

(e) Greater speed is attainable with electric drives because of less effort on the part of the operator, more nearly automatic operation thus eliminating the personal equation and by the characteristics of the motor being such as to take advantage of every part of the cycle to increase speed.

(f) Terminal capacities are increased by the electric motor through the general speeding up of movements, the use of small units in piling and economical stowing of goods, elimination of congestion periods by virtue of its capability to cope with unusual loads for long periods and by rendering available superimposed areas as contrasted with the usual ground level working area of terminals.

(g) Safety goes hand in hand with electric motor methods, due to the automatic features, quickness of control and convenience of control locations. Not the least aid to safety in terminals is adequate lighting, though not a motor application it should nevertheless be more common and more intense.

(h) Electrically equipped terminals offer greater service to patrons by quicker readiness to deliver and receive goods. Commodities are delivered with fewer damages and in more cleanly condition than prevails when hand methods are used. Reservoir effects are increased, i.e., terminals act as pools or 
reservoirs in traffic flow and thereby render a service augmented by electrical machinery, which increases the pool capacity and hastens the filling and emptying work.

(i) The greatest degree of economy is invariably found in electrified terminals, since motors can do for little money what many men ordinarily do for much money. They eliminate troubles incident to the employment of large numbers of unskilled men and the use of ingenious machinery raises the standard of employees and increases their loyalty by eliminating the animal-like drudgery common to the old terminal.

If it were possible to do so, without more misleading effect than aid, some data would be added regarding watts per ton, but there are so many widely varying conditions, such as weight of units, weight of drafts, vertical distance, horizontal distance, rate of motion and auxiliary work such as checking, weighing and inspecting, that interfere with uniform results. In general, the cost of current is negligible as compared with the over-all cost of the large labor force always necessary, the overhead cost of terminal facilities and clerical force and the standby charges of floating and rolling property. However, the power used does aggregate a large amount when taken in connection with adequate lighting of terminal areas, and at least that part that goes to charge batteries is off-peak and very desirable.

Motor applications in freight handling are bound to increase rapidly as terminals are so hemmed in by high-priced property as to preclude ordinary expansion, and intensive cultivation of present areas must follow. The electric motor is the logical and accepted tool for carrying on this betterment. 